\title{
Three-Dimensional Cell Culture Matrices: State of the Art
}

\author{
JUNGWOO LEE, M.S., ${ }^{1}$ MEGHAN J. CUDDIHY, M.S., ${ }^{2}$ and NICHOLAS A. KOTOV, Ph.D. ${ }^{1-3}$
}

\begin{abstract}
Traditional methods of cell growth and manipulation on 2-dimensional (2D) surfaces have been shown to be insufficient for new challenges of cell biology and biochemistry, as well as in pharmaceutical assays. Advances in materials chemistry, materials fabrication and processing technologies, and developmental biology have led to the design of 3D cell culture matrices that better represent the geometry, chemistry, and signaling environment of natural extracellular matrix. In this review, we present the status of state-of-theart 3D cell-growth techniques and scaffolds and analyze them from the perspective of materials properties, manufacturing, and functionality. Particular emphasis was placed on tissue engineering and in vitro modeling of human organs, where we see exceptionally strong potential for 3D scaffolds and cell-growth methods. We also outline key challenges in this field and most likely directions for future development of $3 D$ cell culture over the period of 5-10 years.
\end{abstract}

\section{INTRODUCTION}

$\mathbf{T}$ HE MAJORITY of cell culture studies have been performed on 2-dimensional (2D) surfaces such as micro-well plates, tissue culture flasks, and Petri dishes because of the ease, convenience, and high cell viability of $2 \mathrm{D}$ culture. These conventional 2D cell culture systems have notably improved the understanding of basic cell biology, but disadvantages lie in using a 2D substrate. In the body, nearly all tissue cells reside in an extracellular matrix (ECM) consisting of a complex 3D fibrous meshwork with a wide distribution of fibers and gaps that provide complex biochemical and physical signals. ${ }^{1}$ Additionally, each type of cell is embedded in a considerably different 3D microenvironment. For example, osteoblasts are located on the surface of bone in a sheet-like arrangement of cuboidal cells, hepatocytes are closely packed together in the liver in hexagonal-shaped lobules, and lymphocytes are individually suspended in circulating blood or lymphatic vessels (Fig. 1). ${ }^{2}$ The differentiation niches of stem cells are inherently $3 \mathrm{D}$, and their biochemistry and topology strongly affect the differentiation process. ${ }^{3}$ Two-dimensional substrates are considerably limited in emulating these complex 3D microenvironments because of the lack of structural architecture and finite material selections. Furthermore, inhabiting a 2D rigid substrate requires a dramatic adaptation by surviving cells because of the lack of the unique ECM environment of each cell type. These drawbacks can alter cell metabolism and reduce functionality. ${ }^{4-6}$ For that reason, 2D culture substrates not only fall short of reproducing the complex and dynamic environments of the body, but also are likely to misrepresent findings to some degree by forcing cells to adjust to an artificial flat, rigid surface.

Three-dimensional cell culture matrices, also known as scaffolds, were introduced to overcome 2D culture limitations. These matrices, or scaffolds, are porous substrates that can support cell growth, organization, and differentiation on or within their structure. Architectural and material diversity is much greater on 3D matrices than on 2D substrates. In part, such a variety of biomatrices is due to the large range of tissues being modeled and the need to produce cellular supports with different physical appearance, porosity, permeability, mechanical characteristics, and nano-scale surface morphology. A variety of fabrication processes and biomaterials have been developed or adapted to meet this array of properties. The fabrication process chosen also affects the resulting matrix architecture. For example, electro-spinning ${ }^{7}$ and particulate-leaching ${ }^{8}$ methods create

\footnotetext{
${ }^{1}$ Department of Biomedical Engineering, ${ }^{2}$ Department of Chemical Engineering, ${ }^{3}$ Department of Material Science and Engineering, University of Michigan, Ann Arbor, Michigan.
} 


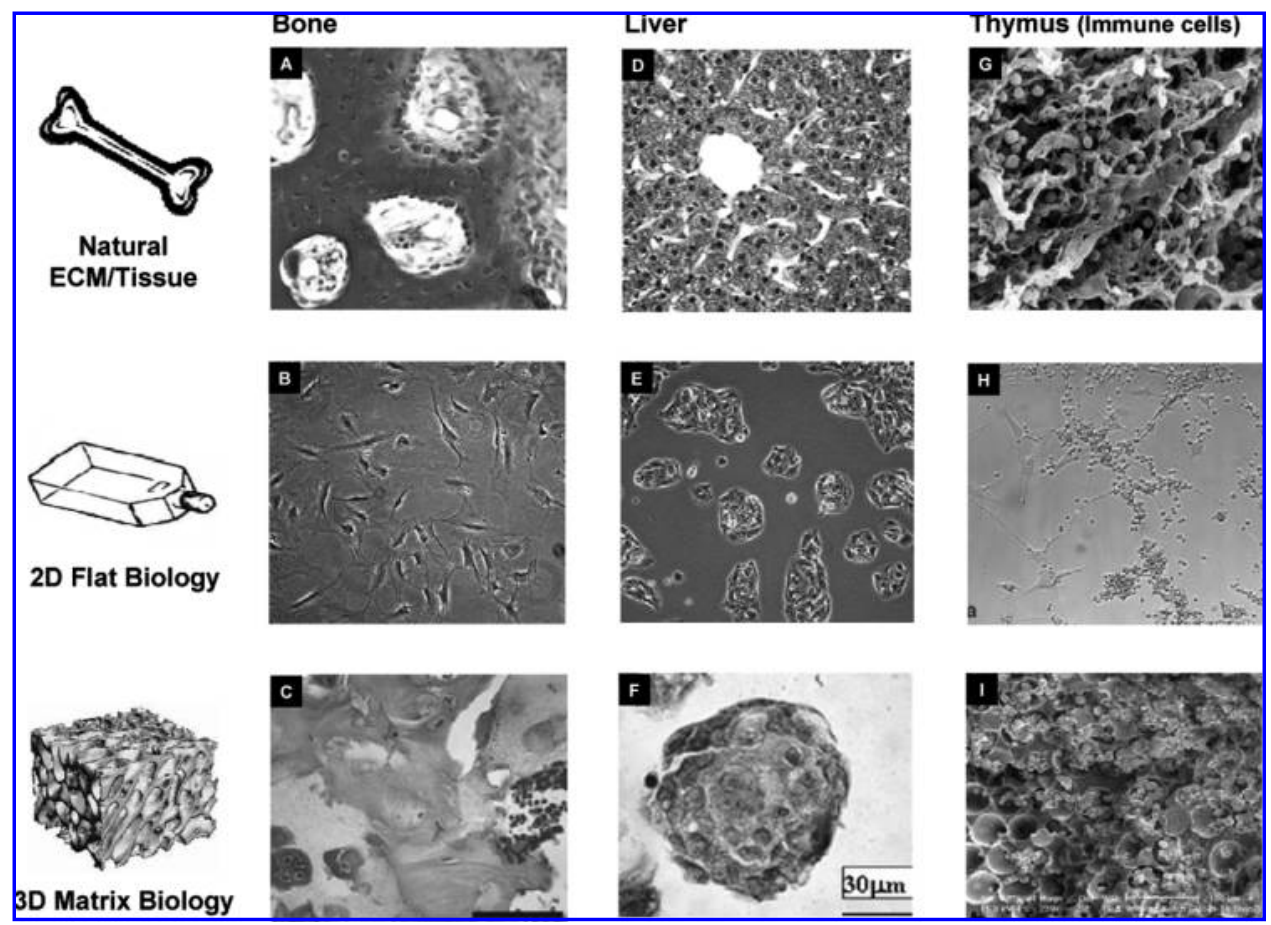

FIG. 1. Comparison of natural cell and tissue morphology cultured on 2D and 3D substrates. Natural tissues and cells have distinct 3D organized morphological features: histological images of (A) bone and (D) liver, ${ }^{2}$ and (G) scanning electron microscope image of the thymus. ${ }^{21}$ When tissue cells are cultured on 2D substrate, they show a similar morphological pattern (stretched). Optical microscope images of $(\mathbf{B})$ osteoblasts, $(\mathbf{E})$ hepatocytes, and $(\mathbf{H})$ co-culture of lymphocytes and stromal cells. ${ }^{21}$ Cellular morphology becomes closer to that of natural tissue when cultured on 3D matrices; different appearance of $(\mathbf{C})$ osteoblasts, ${ }^{22}(\mathbf{F})$ hepatocytes, ${ }^{23}$ and $(\mathbf{I})$ mononuclear cells in a $3 \mathrm{D}$ matrix.

fibrous-mesh and sponge-like structures, respectively, and solid free-form (SFF) fabrication techniques ${ }^{9}$ can manufacture matrices with ordered architectures. In addition to fabrication processes, biomaterials have expanded the diversity of $3 \mathrm{D}$ cell culture matrices. ${ }^{10,11}$ The selected fabrication technique and the particular application of the 3D matrix determine the selection of biomaterial. For instance, only a few biodegradable polymers are suitable for the purpose of making implantable 3D matrices. ${ }^{12}$ In addition, engineering materials and fabrication processes can endow 3D cell culture matrices with complex functionalities, such as releasing growth factors that induce cellular differentiation. ${ }^{13-15}$ New material-processing technologies are being actively investigated to meet multiple requirements in various applications.

Applications of 3D matrices can be divided into clinical and in vitro 3D modeling approaches. Clinical applications mainly consist of tissue engineering or regenerative medicine, which target the creation of a functional implants using artificial 3D matrices. ${ }^{16,17}$ Scaffolds are designed to be implanted in a patient as a temporary template to restore or maintain original tissue function. Accordingly, scaffolds should not only have proper architecture for supporting cell growth, but should also match the shape of the defect site. Materials should be biodegradable and metabolized in the body without causing serious systemic or immunogenic problems. ${ }^{18}$ The other application of a 3D cell culture scaf- folds is their use as an in vitro 3D model system. Here, the aim is to facilitate systematic analysis of cell biology at the molecular level that will significantly improve the understanding of tissue physiology and pathophysiology. ${ }^{19,20}$ For experiments within this application, the 3D matrix should be designed to mimic the 3D organization and the differentiated function of tissues in the body. Three-dimensional matrix accessibility through optical or other imaging tools and processability to precisely control matrix properties are important in this experimental context.

In this review, we first introduce the design criteria of 3D cell culture matrices in structural and material respects. The next section covers how those design criteria have been applied to construct 3D matrices through representative 3D matrix fabrication techniques. Recent progress and strategies of each application are briefly addressed. By providing a broad overview, the review aims to deliver a new objective insight of 3D cell culture matrices and to predict the most promising directions for and the upcoming challenges of future research.

\section{DESIGN CRITERIA}

The eventual goal of artificial 3D cell culture matrix design is to mimic natural ECM features sufficiently that cells 


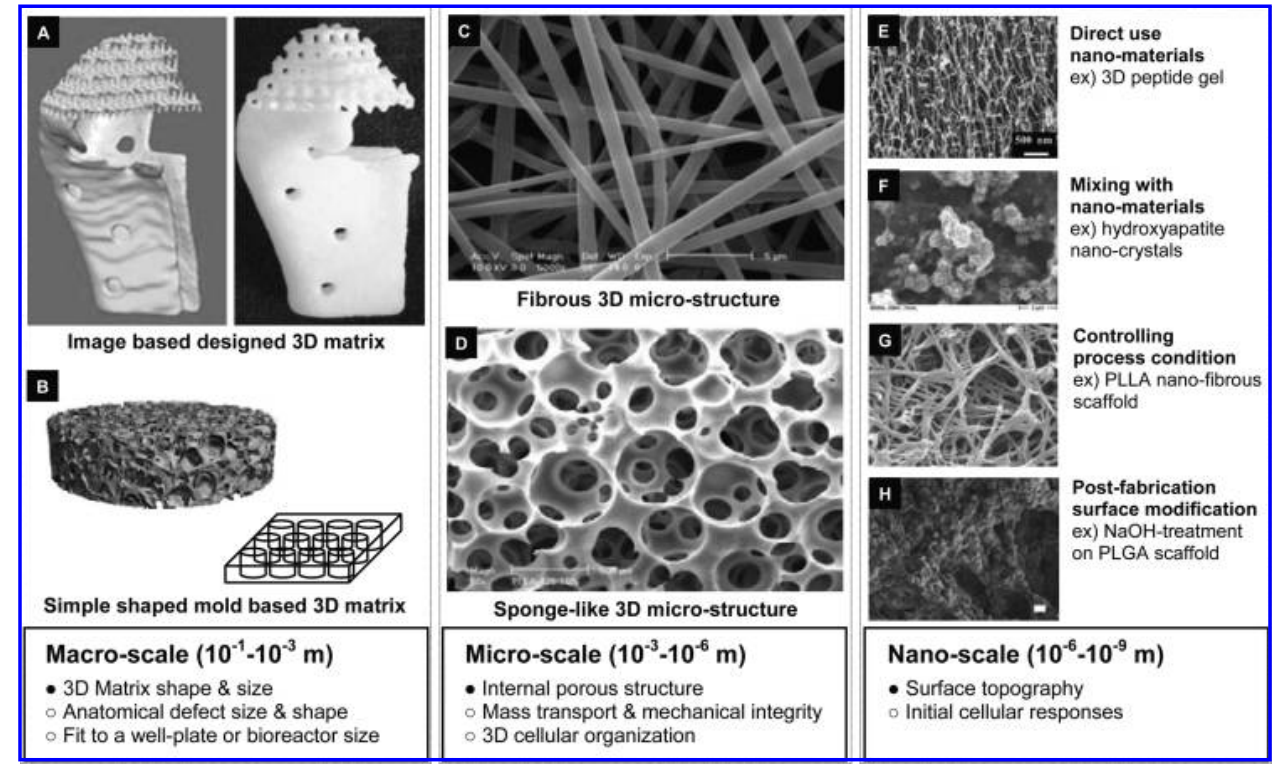

FIG. 2. Design criteria of 3-dimensional cell culture matrix structure in multi-scale $\left(A,{ }^{9} \mathbf{B},{ }^{46} \mathrm{C}^{47} \mathrm{D},{ }^{48} \mathbf{E},{ }^{40} \mathbf{F},{ }^{41} \mathbf{G},{ }^{48} \mathbf{H}^{49}\right)$.

function in the simulated environment as they would in vivo. Natural ECM is an intricate interwoven fiber meshwork of collagen and elastic fibers embedded in a highly hydrated gel-like material of glycosaminoglycans, proteoglycans, and glycoproteins. ${ }^{1}$

The unique compositional and structural combination supplies appropriate biophysical and biochemical functions, such as facilitating the transport of soluble signaling molecules, nutrients, and metabolic wastes and providing mechanical integrity by absorbing compressive and tensile stresses. ${ }^{2}$ The interaction between cells and the ECM is dynamic. For example, the ECM structure can guide morphological changes and cellular organization, ${ }^{24}$ and specific signaling molecules on the ECM can direct cell differentiation into a particular lineage. ${ }^{25}$ Cells also can respond to their local environment, remodeling local ECM by degrading or synthesizing new ECM elements. ${ }^{26}$ Because each tissue has a unique ECM environment, $3 \mathrm{D}$ cell culture matrix design should imitate certain features of the ECM specific to each application. Nevertheless, there are also common characteristics to be considered, such as high porosity and biocompatibility. ${ }^{27}$ In this section, we examine these common features in structural and material aspects. We focus on structural properties that need to be considered at multiple scales for successful replication of natural ECM. Essential material properties and some functional modification strategies are discussed as well.

\section{Structure}

A multi-scale approach to $3 \mathrm{D}$ matrix structure is especially important in mimicking living systems, because nature often derives properties from multi-scale or hierarchical structures. For example, bone has multiple organizational scales that yield superior mechanical properties, from interacting nano-scale collagen and hydroxyapatite crystals to micro-scale lamella and osteons. ${ }^{2}$ With a growing variety of techniques to manipulate natural and synthetic materials, matrix design has become increasingly precise, from the macro- to the nano-scale. Multiple levels of structural control allow for the engineering of unique properties, including matrix size and shape, pore size and geometry, porosity, pore interconnectivity, and surface topology. Here, we define the multiple scales accessible to 3D matrix design in 3 categories: macro-scale $\left(10^{-1}-10^{-3} \mathrm{~m}\right)$, micro-scale $\left(10^{-3}-10^{-6} \mathrm{~m}\right)$, and nano-scale $\left(10^{-6}-10^{-9} \mathrm{~m}\right)$. As we discuss design criteria at each scale, we will discuss several fabrication techniques that provide features at that scale. Details of the specific fabrication methods will be discussed in the section on 3D matrix formation and fabrication techniques below.

Macro-scale design. The macro-scale structure $\left(10^{-1}\right.$ $10^{-3} \mathrm{~m}$ ) determines properties of a 3D matrix including size and shape (Fig. 2A, B). For in-vitro 3D cell culture applications, the size and shape of a matrix can be controlled for convenience and functionality (e.g., fitting to a well plate or bioreactor). In tissue engineering, it is important to match matrix size and shape to the anatomical defect. For example, a scaffold for bone tissue engineering should have a properly designed macro-scale structure to allow for integration with adjacent tissues, as well as to generate properly size tissue. ${ }^{28}$ Appropriate design of anatomic shape also is important for cosmetic purposes. A major challenge of macro-scale control over implantable scaffolds is that the relevant properties (e.g., defect site size and shape) vary from patient to patient. One approach to achieve this level of design control is to use computer-based medical imaging tools such as computed tomography (CT) and magnetic resonance imaging (MRI) 
and design strategies such as computer-aided design (CAD), which become useful in customizing the 3D architecture to match a wound site. ${ }^{9}$ This design can be manufactured using SFF fabrication. The macroscopic structural design of 3D matrices, along with their fast and individualized production, will become more important with the increased use of $3 \mathrm{D}$ cell scaffolds in clinical applications. ${ }^{29-31}$

Micro-scale design. Controllability on the micro-scale $\left(10^{-3}-10^{-6} \mathrm{~m}\right)$ is valuable to mimic microscopic tissue structure, such as the multi-cellular spatial organization within ECM proteins. Tissue architecture and function are closely interrelated. For example, blood vessels consist of the 3 distinct layers of endothelium, smooth muscle, and connective tissue. A circularly oriented smooth muscle layer surrounded by longitudinally oriented inner endothelium and outer connective tissue layers regulate blood flow. ${ }^{2}$ Although micro-scale 3D matrix design should be specific for each application, there are also general but essential design parameters such as porosity, pore interconnectivity, pore geometry, pore size distribution, and some surface topography.

In addition to the diffusion of nutrients, metabolic wastes, and soluble molecules, one of the critical issues in microscale design is the facilitation of mass transport within 3D matrices to control the efficiency of cell seeding. ${ }^{27}$ The inclusion of sufficiently sized open pores and a wellinterconnected geometry improves diffusion throughout the scaffold interior. Pore geometry and pore size distribution are other critical factors. Three-dimensional matrices with similar porosity but dramatically different pore geometry, such as fibrous versus spherical pores, can yield different mass transport profiles (Fig. 2C, D). A large pore size distribution can lead to areas with poorer accessibility, potentially limiting cell seeding and migration efficiency.

Individual cells recognize structures which have comparable dimension to cellular size $(10-100 \mu \mathrm{m}))^{32}$ Therefore, micro-scale surface morphological texture needs to be considered among design criteria. Micro-scale surface features can activate certain genes and modulate cellular behavior in differentiation or proliferation. For example, microscopic surface patterns and grooves on 2D surfaces guide neuronal cell polarization ${ }^{33}$ and myoblast alignment. ${ }^{34}$ Beyond that, there is a poor understanding of how the topology of 3D scaffolds affects cell development. For instance, it is difficult to answer how the change of fibrous substrate to a support with leached pore morphology affects the differentiation of stem cells. We believe this will be one of the fundamental and important directions in future research in 3D matrices in the next 5 years.

Micro-scale structural design also affects the mechanical properties of the bulk scaffold. Sufficient mechanical properties are important in tissue engineering, in which the scaffold may be required to withstand forces generated by the body, and in 3D cell culture, in which the matrix must withstand cell attachment forces, handling by scientists, and media convection in bioreactors. Oftentimes, a stochastic micro-structural architecture, such as those resulting from particulate leaching fabrication techniques, requires high porosity to ensure complete interconnectivity. The high porosity sacrifices mechanical properties by reducing the amount of material present in the matrix. Precise design of matrices, where architecture is optimized to provide complete interconnectivity at higher porosities, can improve mechanical strength while preserving effective diffusion. ${ }^{35}$

Overall, some of the most fundamental matrix design criteria require control on the micro-scale. With improving technologies, it is becoming increasingly obvious that precise micro-scale design is necessary to maximize these microscale properties. Although there are numerous fabrication methods to make 3D matrices with micro-scale resolution, some manufacturing methods, such as SFF fabrication ${ }^{36}$ and inverted colloidal crystal (ICC) fabrication, ${ }^{37}$ provide precise controllability over 3D matrix architecture at this scale. These techniques and others will be discussed in the fabrication section.

Nano-scale design. Cells interact with ECM via nanoscale proteins, responding to their environment by modulating various cellular activities. Therefore, specific attention to matrix design on the nano-scale $\left(10^{-6}-10^{-9} \mathrm{~m}\right)$ is logical, because most individual ECM components are in nano-meter scale. For example, collagen fibrils have a diameter range of 50 to $200 \mathrm{~nm}$, and fibronectin are 60 to $70 \mathrm{~nm}$ long and 2 to $3 \mathrm{~nm}$ thick. ${ }^{1}$

Aside from the inhibition of nutrient supply by microscale geometry, nano-scale structural features provide the most significant influence on cell functions as a part of surface topography. This is not surprising because many cell-signaling mechanisms involve nano-scale molecules. Nano-scale surface topography has been demonstrated to regulate cell adhesion, organization, morphology, and differentiation. ${ }^{38}$ Still, compared with surface chemistry, limited 3D nano-scale fabrication techniques leave the effects of surface topology insufficiently investigated. Currently, nano-sized 3D surface structural features can be achieved in 4 ways. The first method involves using nano-materials such as $3 \mathrm{D}$ peptide hydrogels directly, entrapping cells in a 3D nano-scale fibrous structure ${ }^{39,40}$ (Fig. 2E). The second method incorporates nano-sized materials into bulk materials before matrix manufacture ${ }^{41}$ (Fig. 2F). A great deal of research in bone tissue engineering has focused on integrating nano-sized features into scaffolds to improve osteoblast adhesion, proliferation, and calcium deposition. For example, hydroxyapatite nano-particles incorporated into the matrix of poly-L-lactic acid (PLLA) scaffolds yielded nano-scale topology that significantly increased protein adsorption. ${ }^{42}$ The third method controls processing conditions during fabrication (Fig. 2G). A nano-scale fibrous structure can be produced on the surface of a 3D matrix through thermally induced phase separation of PLLA solution in organic solvent, followed by a crystallization process during 
Table 1. Materials for Three-dimensional Matrix Building

\begin{tabular}{lc}
\hline Synthetic Polymers & Natural Polymers \\
\hline Poly (glycolic acid) (PGA), Poly (lactic acid) (PLA), Poly & Collagen, Gelatin, Hyaluronate, Glycosaminoglycan, Chitosan, \\
(lactic-co-glycolic acid) (PLGA), poly ( 8 -carpolactone) & Alginate, Silk, Fibrin, Dextran, Matrigel, etc. \\
(PCL), poly (ethylene glycol) (PEG), poly (vinylalchol) & \\
(PVA), poly (propylene fumarate) (PPF), poly(acrylic acid) & \\
(PAA), etc. *Peptide, DNA (artificially prepared natural & \\
polymers) &
\end{tabular}

freeze drying. ${ }^{43}$ Electrospinning techniques can also reduce fiber diameter to the nano-scale. ${ }^{44}$ The last approach is postfabrication surface treatment or surface coating (Fig. $2 \mathrm{H}$ ). For example, brief exposure of 3D polyester scaffolds to sodium hydroxide $(\mathrm{NaOH})$ created nano-scale surface roughness, which improved the adhesion of osteoblasts and chondrocytes. ${ }^{45}$ Although the above techniques are successful at generating nano-scale surface structures, feature controllability on 3D structures presents a major challenge.

Proper design of 3D cell culture matrix structure on multiple scales can provide distinct features to the matrix, such as macro-scale shape, micro-scale internal architecture, and nano-scale surface topology. Therefore, 3D biomatrix design should incorporate all scales to mimic the hierarchical structure of natural tissue that is correlated with cellular organization and functionality. However, controllability is highly dependent on material properties and selected fabrication processing, as will be discussed in later sections. Development of processing approaches that will allow freedom in choice of macro-, micro-, and nano-scale is one of the most difficult challenges in 3D scaffolds that the materials science and nano-technologist communities need to addressed.

\section{Biomaterials}

As researchers are diverging from traditional 2D tissue cultures on glass and polystyrene, cellular responses to materials are becoming increasingly apparent. Many new biomaterials have been developed to mimic the unique characteristics of natural ECM. In general, these biomaterials can be divided into 4 groups: metals, ceramics, polymers, and composites. ${ }^{50}$ Among them, polymeric materials receive substantial attention because of the great flexibility in designing the composition and structure for specific needs.

Polymeric materials can be divided into natural and synthetic polymers (Table 1). Innate properties of these natural and synthetic polymers have been reviewed extensively elsewhere, ${ }^{12,50-52}$ whereas commonly required features to design 3D matrices have not been comprehensively examined. Beyond the greater controllability in chemical and physical properties of these synthetic polymers, the development of various materials engineering and hybridization techniques produce materials that emulate ECM functions in an artificial environment. Here, we address the key pa- rameters in selecting and engineering polymeric 3D matrix materials from the viewpoint of bulk and surface properties.

\section{Bulk properties}

Bulk material selection is the first consideration of $3 \mathrm{D}$ matrix design because it dictates various fundamental properties of the matrix from biological effects to processability. Here, we discuss several key parameters of bulk materials for matrix design, including biocompatibility, wettability, transparency, biodegradability, and mechanical properties, as well as examples of bulk material modifications that are used to emulate natural ECM.

Biocompatibility of the bulk material is a critical parameter, because it determines the ability of materials to perform their desired functions with appropriate cellular or host responses. Biocompatibility can be understood as a graded characteristic, for which the requirements change depending on the specific application. The degree of biocompatibility can vary from the lack of toxicity with respect to transformed cell cultures to the lack of long-term immunological systemic response of the human body. The strictest requirements are applied to implantable scaffolds to avoid undesired responses, such as a strong immune reaction or fibrous encapsulation. Ideally, the body should be able to metabolize degraded substances. Natural materials tend to show better biocompatibility than synthetic materials, but their animal sources raise concerns about disease transfection. ${ }^{53}$ The more relaxed definition of biocompatibility is applied to $3 \mathrm{D}$ scaffolds to be used ex vivo, but the more complex the cellular system is, the more stringent the compatibility requirements are. Fabrication processes that use harsh chemicals decrease biocompatibility and sometimes cause matrix toxicity even if the bulk materials are biocompatible.

Because natural ECM is a fully hydrated gel, wettability is a key consideration. ${ }^{54}$ Bulk materials with more hydrophilic chemistry are better at mimicking the aqueous in vivo environment. For this reason, hydrogels, networks of hydrophilic polymer chains, have been used extensively as 3D matrix materials. ${ }^{51,55}$ The hydrogel structure also creates a gradient of soluble signaling molecules within a 3D matrix and absorbs mechanical tensions. Nevertheless, poor cell adhesion due to the hydrophilicity of hydrogels and the lack of cell binding motifs is a common drawback. ${ }^{51}$ These limitations 
can be overcome by conjugating cell-binding motifs such as arginine-glycine-aspartate (RGD) on polymer chains ${ }^{56}$ or by coating surfaces with bioactive materials post-fabrication. ${ }^{57}$

Transparency of bulk materials is an important parameter for 3D in vitro modeling applications in whic cellular behaviors within the 3D matrix require microscopic detection. Many sensing and quantification techniques, such as immunostaining and enzyme-linked immunosorbent assay, also use optical-based instrumentation, including confocal microscopes and micro-plate readers. Thus, transparent materials are advantageous to collect optical signals passing through the bulk structure without dissipating light beam. One may also consider a broader definition of transparency beyond the traditional ultraviolet-visible spectroscopy ultraviolet-visible spectroscopy (UV-vis) range of electromagnetic waves between 300 and $800 \mathrm{~nm}$. Transparency in the X-ray region is reasonably high for most materials, which will be important to use for analysis of cell behavior in 3D scaffolds. X-rays can penetrate to depths that are not possible for confocal microscopy images even in the most transparent media. However, X-ray contrast of live cells in most 3D matrices is poor. The development of appropriate contrast agents for cells for 3D X-ray tomography using nano-particles is a burgeoning research area with much promise. ${ }^{58-61}$ Much contribution can be made in this field by further improving image contrast and resolution particle delivery to the cells and introducing X-ray "color" with different nano-particles, which will greatly improve the research process in 3D scaffolds.

Controlled biodegradability is an essential requirement for implantable 3D scaffolds, because these scaffolds are generally designed to degrade at the rate that in-growing tissue replaces them. Generally, synthetic materials degrade hydrolytically, ${ }^{62}$ and natural materials undergo an enzymatic degradation process. ${ }^{63}$ Hydrolytic degradation is more predictable and adjustable than enzymatic degradation. For example, the degradation profile of poly(lactic-co-glycolic acid) (PLGA) scaffolds can be manipulated by adjusting the composition and molecular weight of poly(lactic acid) (PLA) and poly(glycolic acid) (PGA) polymers. ${ }^{64}$ On the other hand, enzymatic degradation of natural materials is more dependent on local enzyme concentration secreted from cells. ${ }^{65}$ Thus, the degradation profile and mechanism under physiological conditions for scaffold materials, as well as the implantation site and desired scaffold function, need to be carefully considered when designing an implantable scaffold.

Mechanical properties of bulk materials represent an important set of characteristics to consider in 3D matrix design. First, bulk materials are fundamental contributors to the mechanical integrity of 3D matrix structure. This is especially so in tissue engineering for structural tissues. For instance, bone regeneration scaffolds may endure substantial mechanical stresses immediately after implantation. ${ }^{66}$ If the scaffold cannot bear sufficient loads, it might fracture before the bone healing process is complete; however, excessively strong mechanical properties can damage adjacent bone or retard new bone regeneration via stress shielding. This becomes even more complicated when bulk materials start to degrade, because the mechanical properties of the scaffold should retain integrity and gradually transfer loads to ingrowing bone. Therefore, the scaffolds should have mechanical properties resembling those of healthy tissue over the period of tissue regeneration.

Second, the bulk mechanical properties directly shape surface mechanical properties, such as surface stiffness or elasticity, which elicit clear cellular responses. For example, cells on 2D cultures initially recognize adhesive proteins on the substrate through transmembrane integrin receptors receiving mechanical signals, which activate actin-filament polymerization and promote focal adhesion formation. Later, cells apply traction forces to pull the ligands from a substrate and sense the surface stiffness. ${ }^{67}$ Recently, a modified fluorescence resonance energy transfer technique was used to measure cell tracking forces quantitatively on 2D substrates with different degrees of stiffness. It demonstrated that stiffer substrates support preosteoblast proliferation and that softer substrates promote differentiation. ${ }^{68}$ In another seminal work, the response of human mesenchymal stem cells (hMSCs) on a 2D hydrogel matrix with different grades of elasticity was studied. hMSCs displayed a phenotype of neurogenic lineage on the softest substrates, a myogenic phenotype on moderately stiff matrices, and an osteogenic phenotype on the stiffest substrates. ${ }^{69}$ Even though these results were derived from a $2 \mathrm{D}$ model system, they provide valuable information for 3D matrix design. For example, the timing of different functions of the scaffolds, such as early proliferation and late differentiation, can be developed as a strategy for many tissue regeneration applications. A gradual switch from cell proliferation to cell differentiation can be obtained by progressive softening of the scaffolds during the biodegradation process.

Bulk properties are frequently modified to replicate the multi-functional tasks of natural ECM on an artificial 3D matrix. There are numerous materials engineering and hybridization techniques, but here we discuss 3 distinct strategies. The first approach involves hybridizing natural and synthetic materials to improve the biological and physical properties of a 3D matrix. For example, limited bioactivity of synthetic materials can be improved by covalently incorporating multifunctional ligands from natural materials (e.g., fibronectin, vitronectin, and laminin) onto synthetic polymers. ${ }^{70-72}$ Depending on the application, the ligand type and concentration can be adjusted. Weak mechanical properties of natural materials can be improved by incorporating synthetic polymers. Photopolymerizable hyaluronan and collagen conjugated with synthetic cross-linkers can be copolymerized with synthetic polymers. ${ }^{73,74}$ This significantly enhances the physical stability of the 3D structure in a controlled manner while preserving the inherent biological properties of natural materials. Currently, critical concerns are control over the spatial distribution of ligands and their configuration change after immobilization in a 3D matrix. 
The second approach is the incorporation of soluble signaling molecules within a 3D matrix. In nature, the temporal release of soluble signaling molecules from ECM in a spatial gradient significantly influences various cellular behaviors. In $2 \mathrm{D}$ culture, the delivery of soluble signaling molecules is rapid and uniform but lacks a spatial gradient. It can be advantageous to create gradient signaling profiles in $3 \mathrm{D}$ culture, although diffusion may be considerably impeded. For this purpose, soluble bioactive molecules, such as growth factors and deoxyribonucleic acid (DNA) encoded for the desired protein synthesis, are mixed in 3D matrix materials. ${ }^{15,75}$ Often these molecules are pre-encapsulated within biodegradable polymeric carriers, such as PLGA, for longer periods of release with a controlled profile. Encapsulation can also minimize the deformation of the $3 \mathrm{D}$ configuration of protein during the fabrication process. Moreover, multiple components can be secreted at different time points by taking advantage of different release kinetics. For example, Richardson et al. developed a dual growth factor-delivery system with different release kinetics in PLGA scaffolds: rapid release of vascular endothelial growth factor (VEGF) without a carrier and slow release of pre-encapsulated platelet-derived growth factor (PDGF). ${ }^{76}$ VEGF first stimulated endothelial cell proliferation and channel formation, and PDGF recruited smooth muscle cells around the channels, which remodeled and matured the nascent vascular networks. As a result, the diameter and density of vessels were significantly greater than those of vessels in single growth factor releasing and blank scaffolds.

The delivery of DNA is also beneficial in maintaining physical integrity and enhancing effectiveness, because DNA is merely a 1D linear base sequence; preservation of configuration is not as much of a concern. Like proteins, DNA delivery is normally combined with viral vectors such as retroviruses and adenoviruses, but non-viral vectors, such as cationic polymers and lipid complexes, are also used to deliver the DNA sequence to cell nuclei. ${ }^{77}$ Current challenges include the improvement of controllability in the carrier system and the enhancement of efficacy in delivered signaling molecules.

The third method that can be used to make an analogous ECM is to hybridize biomaterials with various functional nano-materials. For example, bone tissue ECM is composed of organic collagen and inorganic hydroxyapatite. ${ }^{2}$ Polymeric materials only represent the organic element of bone tissue ECM; therefore, hydroxyapatite nano-particles are often incorporated, demonstrating greater osteoblastic differentiation than polymeric materials alone. ${ }^{42}$ Recently, carbon nanotubes (CNTs) have been used as a hybridization material for 3D matrices because of their unique physical and chemical properties and flexibility of surface functionalization. The excellent mechanical strength of CNTs lends them to be incorporated into scaffolding materials for structural reinforcement. ${ }^{78}$ Additionally, the metallic properties of CNTs allow them to be used as a contrast enhancement reagent for non-optical-based imaging tools. ${ }^{79}$ Electrically conductive
CNT composite films have also been applied for stimulation of neuron cells by electrical pulses. ${ }^{80,81}$ Moreover, CNTs support neuronal cell outgrowth and differentiation because their fibrous or tubular structure is similar to those of neural processes with comparable dimensions. ${ }^{82}$ Although great potential exists for using nano-materials, several problems should be clarified, such as dispersion in nano-composite solutions, effective functionalization, biocompatibility, and potential systemic effects of nano-colloids in the body. We strongly believe that nano-materials represent a great resource for biomedical engineering; however, in the next 5 to 10 years, various breakthroughs in understanding the interactions between nano-materials and cells and the interplay between 3D and nano- and micro topology on cell effects should be expected.

Surface properties. Surface properties are crucial in controlling interactions between cells and a substrate. Although surface properties are often derived from the bulk properties of materials, the bulk materials do not entirely define them, because 3D matrices are coated with proteins almost immediately after implantation in the body or immersion in culture media. ${ }^{83}$ Surface chemistry and topography determine the identity, quantity, and conformational change of these adsorbed proteins.

Surface properties include stiffness, charge, polarity, and chemistry, among a multitude of others. For example, the surface charge density determines the amount of protein adsorption and resultant cell adhesion. ${ }^{84}$ Greater surface charge brings a greater density of protein coating, leading to better cell adhesion. ${ }^{85}$ Positively charged surfaces support better osteoblast adhesion than do negatively charged surfaces with similar charge density. It is believed that different protein species adhere to the scaffold depending on surface charge polarity, causing this distinction. ${ }^{86}$ Surface chemistry also modulates the bioactivity of coated proteins by causing different configurations of adsorbed proteins. For instance, an equal amount of fibronectin pre-coated on 4 different substrate having $\mathrm{OH}, \mathrm{NH}_{2}, \mathrm{COOH}$, and $\mathrm{CH}_{3}$ functional groups resulted in adherence of different configurations of fibronectin and led to a specific class of integrin activation on osteoblasts. As a result, $\mathrm{OH}$ and $\mathrm{NH}_{2}$ terminated surfaces supported better osteoblastic differentiation, alkaline phosphatase activity, and matrix mineralization than $\mathrm{COOH}$ and $\mathrm{CH}_{3}$ groups. ${ }^{87}$

Surface properties can be modulated through the attachment of specific functional groups or proteins with necessary biological functions to regulate cellular behavior. Fewer techniques are applicable to $3 \mathrm{D}$ substrates than to $2 \mathrm{D}$ biological surface modification methods because of limited diffusivity within the porous internal structures. Layer-bylayer (LBL) surface coating is a promising technique to modify 3D matrix surface properties with various materials. ${ }^{88} \mathrm{LBL}$ is described as the sequential dipping of a substrate into baths of oppositely charged solutions alternating with rinses in water, yielding monolayer control over the 
surface properties of the substrate. ${ }^{89}$ Complex 3D porous structures can be coated using the LBL technique as long as there is no serious mass transport limitation. LBL has been used to apply clay nano-particles to increase cell adhesion and proliferation on hydrogel scaffolds. ${ }^{57,90}$ Also, various biomolecules can be incorporated in LBL films with minimal loss of bioactivity and can be delivered to cells in a sustained manner by using hydrolytically degradable polyelectrolytes. ${ }^{91}$ For example, LBL films containing bone morphological protein-2 (BMP-2) and transforming growth factor- $\beta 1$ (TGF- $\beta 1$ ) mediated bone tissue formation of embryonic stem cells. ${ }^{92}$

Vapor phase deposition is another technique to modify 3D substrates. Because this surface-coating process operates in the vapor phase, 3D matrices should be dried before processing. In a low-pressure chamber, monomeric compounds diffuse easily into the internal area of a 3D matrix, aided by air flow to reinforce diffusivity. ${ }^{93}$ Plasma processing has been applied to coat 3D porous PLA scaffolds with amine groups to improve embryo 3T3 fibroblast adhesion. Amino groups grafted to the surface promoted adsorption of adhesive proteins, approximately doubling the number of cells initially adhering to the scaffold. ${ }^{46}$

Another interesting approach is coating 3D matrix surfaces with natural ECM by culturing stromal cells and removing them from the matrix.

Because the natural ECM consists of a complicated mixture of organic and inorganic components originally produced from cells, scaffolds coated with bone-like ECM secreted by osteoblasts significantly enhanced differentiation of rat mesenchymal stem cells (MSCs) into osteoblasts. ${ }^{94}$

There are a large number of criteria for the design of 3D cell culture matrices. On a structural level, there are multiple scales of features that influence the matrix function on cells, as well as the function of cells residing within the matrix. From a biomaterials point of view, bulk and surface properties have to be considered. Although they are not mutually exclusive, structural and biomaterial features can be chosen and manipulated depending on the desired application of the matrix. As we will see in the next section, 3D matrix design becomes increasingly complex depending on the chosen matrix fabrication technique, because the technique chosen limits the level of structural control and applicable biomaterials.

\section{D MATRIX FORMATION AND FABRICATION TECHNIQUES}

Parallel to the development of advanced materials and process engineering, 3D matrix formation and fabrication techniques have evolved considerably to manufacture moreelaborate 3D structures with a broad range of biomaterials. The earliest is the encapsulation of cells within a hydrogel matrix. In this culture format, a hydrated nano-scale fibrous structure similar to natural ECM surrounds cells are completely. Typical cellular behaviors, unrecognized on conven- tional 2D culture, became reproducible in this $3 \mathrm{D}$ culture environment. ${ }^{95}$ Under the tissue-engineering theme, various micro-scale 3D porous matrix fabrication procedures were introduced. Many types of scaffolds are under investigation to construct pilot model tissues for bone, ${ }^{96}$ cartilage, ${ }^{97}$ skin, ${ }^{98}$ liver, ${ }^{99}$ blood vessel, ${ }^{100}$ and muscle. ${ }^{101}$ Computer-assisted fabrication systems emerged with the greater necessity for complex and customized 3D matrix structure design and manufacture. Currently, the SFF technique, also called rapid prototyping, is the most broadly used of computerassisted methods. SFF ultimately allows for control over macroscopic properties, such as scaffold shape, as well as microscopic internal architecture. ${ }^{9}$ Conventional microfabrication technologies, such as soft lithography and photo lithography, have excellent control over micro-scale structure. ${ }^{102,103}$ Nevertheless, these manufacturing processes are limited to constructing freestanding 3D matrices. We define these structures produced as 2.5D and excluded them from the scope of this review, except for a newly emerging multiphoton absorption polymerization (MAP) that can create an intricate 3D structure with a high aspect ratio. ${ }^{104}$

Although all of the fabrication methods have unique advantages, there is no one standard or superior fabrication process, and new methods are being researched. In this section, we review current 3D matrix fabrication techniques from the viewpoint of structural and materials design criteria and introduce some valuable modifications. Selected examples in each 3D matrix are also discussed in terms of in vitro models and tissue-engineering applications.

\section{$3 D$ cell entrapment}

Technique. The process of 3D cell entrapment is conceptually simple. A hydrogel precursor solution is mixed with a cell suspension and then quickly gelled using random or self-assembling polymerization via changes of physical or chemical conditions. ${ }^{105}$ The unique advantage of this technique is that cell culture is performed within a $3 \mathrm{D}$ environment that completely surrounds cells, enabling the delivery of intense signals to cells from all directions.

Structure. It is difficult to control the 3D matrix structure because of the rapid cell entrapment and gelling process. Normally, the mold in which they are formed defines macroscale structures. In the case that cell-entrapping precursor solution is dropped into an initiator solution, the structure takes on a spherical shape. ${ }^{106}$ There is no distinct microporous structure; thus, mass transport mainly depends on slow diffusion through submicron-size pores. Still, the high water content (95.0-99.5\%) enables sufficient exchange of essential biomolecules and metabolic end products to maintain cell viability in a limited thickness. ${ }^{107}$ On the nanoscale, the interwoven mesh structure is beneficial for emulating an in vivo physical environment. For example, fiber diameters of 10 to $150 \mathrm{~nm}$ are in a range similar to the size of ECM fibers, providing a similar atmosphere for cell growth. 


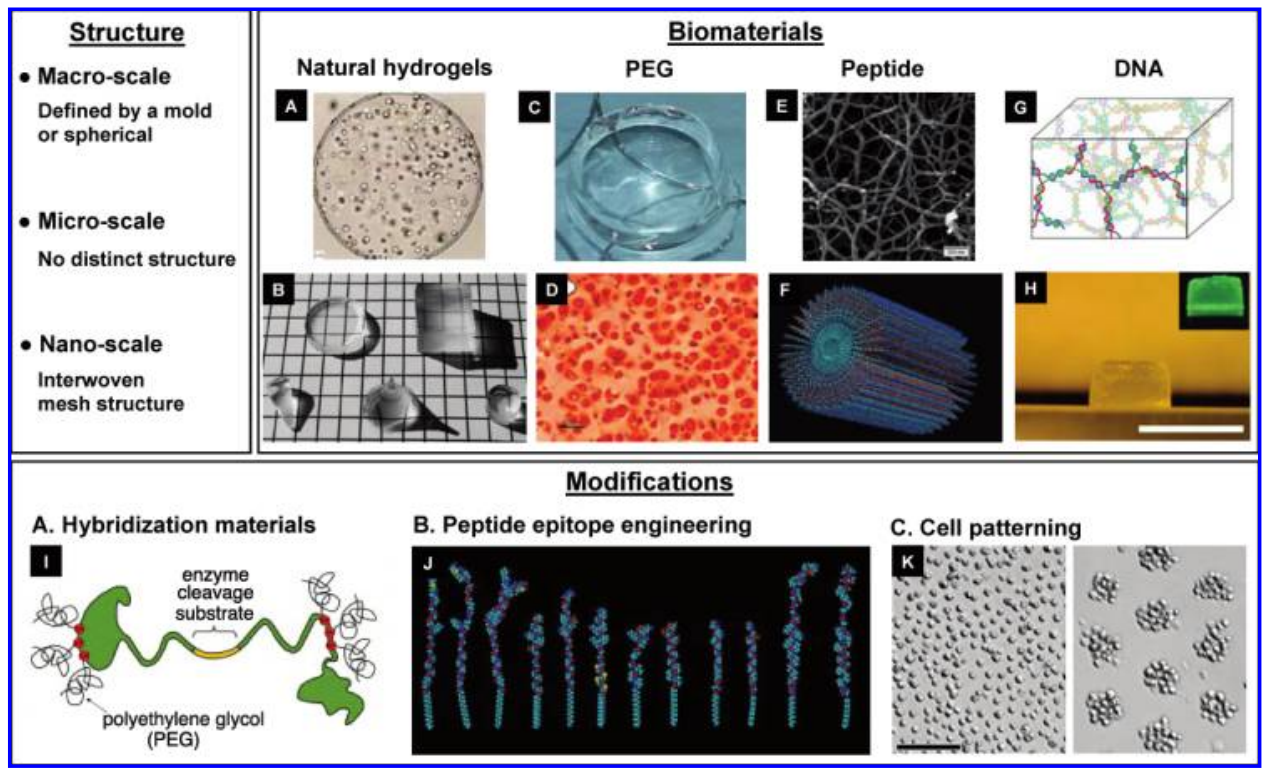

FIG. 3. Overview of 3-dimensional cell entrapping hydrogels. (A) Fibroblast cells encapsulating alginate micro-spheres. ${ }^{106}$ (B) Ionically cross-linked alginate hydrogels with defined macroscopic shape transferred from a mold. ${ }^{122}$ (C) Photo-polymerized polyethylene glycol (PEG) hydrogel. ${ }^{123}$ (D) Safranin-O stained cartilage cells entrapped in PEG hydrogel. ${ }^{124}$ (E) Scanning electron microscopy image of a peptide amphiphile nano-fiber network. ${ }^{125}(\mathbf{F})$ Illustration of self-assembled peptide amphiphiles forming cylindrical nanotubes. ${ }^{125}$ (G) Schematic of deoxyribonucleic acid (DNA) hydrogel structure. ${ }^{126}$ (H) DNA hydrogel made in a cylindrical mold. ${ }^{116}$ (I) Scheme for the preparation of matrix metalloproteinase (MMP)-sensitive PEG hydrogel. ${ }^{127}$ (J) Examples of variation of self-assembling peptide amphiphile units. $^{125}(\mathbf{K}) .3$ D patterned hepatocytes in PEG hydrogel, before (left) and after (right) patterning. ${ }^{121}$

Pore sizes of 5 to $400 \mathrm{~nm}$ are comparable to those of natural ECM, reproducing the slow diffusion of soluble molecules to create a gradient signaling profile within the 3D matrix. ${ }^{107}$ Although the ECM-like environment is an ideal condition for cell culture, weak mechanical properties are a major limitation of the exceptionally hydrophilic nature of the matrix

Biomaterials. Three-dimensional cell entrapping materials are natural or synthetic hydrogels that can undergo fast yet gentle polymerization around cells. The monomeric components must be nontoxic and biocompatible, because cells are mixed with the precursor solution before gelling. The polymers can be hydrolytically or enzymatically degradable. In addition, 3D hydrogel matrices show excellent wettability, and many demonstrate superior transparency in the UV-vis range. Surface properties of entrapping hydrogel are derived from bulk properties because 3D matrix completely surround cells. Stiffness and topography of the matrix can be manipulated by adjusting the concentration of monomer and cross-linker.

Natural hydrogels, like Matrigel, fibrin gel, and alginate gel, are commonly applied as cell-entrapping materials because of their outstanding biocompatibility and mild gelling conditions. However, some of the major drawbacks include poor control of gelation kinetics, uncontrolled material composition, and lack of mechanical integrity. Matrigel is composed of solubilized basement membrane proteins ex- tracted from a rat chondrosarcoma. These soluble proteins undergo self-assembled polymerization when incubated at $37^{\circ} \mathrm{C}$, forming a 3D gel. ${ }^{108}$ Although Matrigel is an excellent biomaterial because of its abundance of natural biological molecules, its heterogeneous and unidentified molecular components reduce a degree of experimental control. Additionally, the animal-derived source of the material may be contaminated with viruses, potentially affecting experimental results. For example, mouse-derived Matrigel is sometimes contaminated with a lactate dehydrogenase-elevating virus. ${ }^{53}$ Fibrin gel is made by mixing 2 blood coagulation components: fibrinogen and thrombin. Polymerization initiates when fibrinogen is converted to fibrin upon addition of thrombin. As fibrin polymerizes, interactions between polymers cause gelling into a 3-dimensionally organized clot, commonly seen in classic wound healing. ${ }^{109}$ Alginate, a family of linear copolymers composed of 2 monomers $(\alpha-\mathrm{L}$ guluronic acid and $\beta$-D-mannuronic acid), is extracted from seaweed. The gelation of alginate occurs by adding ionic cross-linkers or divalent cations such as $\mathrm{Ca}^{2+}, \mathrm{Ba}^{2+}$, and $\mathrm{Sr}^{2+}$. The quantity and binding affinity of ionic cross-linkers determine gel properties ${ }^{110}$ (Fig. 3A, B).

Synthetic hydrogels have been introduced for greater control over physical and chemical properties of 3D culture environments. The homogeneous nature of synthetic hydrogels provides much better matrix uniformity and simpler biochemical assays than natural hydrogels. Additionally, it significantly promotes reproducibility of experimental 
results. For example, a 3D matrix constructed of simple peptide-based building blocks provides a blank background, minimizing noise in biochemical analysis. Thus, an assay determining the accumulation of cartilage ECM macromolecules (e.g., proteoglycans and glycosaminoglycans) synthesized from differentiated chondrocytes can be performed without concern about initial contamination of those molecules in the matrix. ${ }^{111}$ Synthetic hydrogels normally are not explicitly bioactive, and harsh polymerization conditions (i.e., free radical initiation and limited biocompatibility of monomeric components) frequently prevent the use of synthetic hydrogels as cell-entrapping materials.

Currently, 3 types of synthetic gels are used: poly(ethylene glycol) (PEG), peptide, and DNA gels. PEG hydrogel has been used because of its high biocompatibility and precise control of reaction kinetics during rapid photopolymerization, providing a spatially well-controlled 3D gel for cell entrapment ${ }^{112}$ (Fig. 3C, D). Peptide gels are composed of macroscopically self-assembled synthetic peptides. Small quantities of elemental peptides (0.1-5.0\%) dispersed in water are mixed with a cell suspension, which then undergoes a self-assembling process under the right ionic conditions. Self-assembled peptides generate a stable nano-fibrous structure, entrapping cells. Two types of synthetic peptides currently used in this fashion are amyloid-like fibrils ${ }^{113}$ and peptide amphiphiles ${ }^{114}$ (Fig. 3E, F). Recently, DNA has been used as a building block to construct hydrogels with the invention of an oligonucleotide synthesizer to design a specific sequence of DNA and polymerase chain reaction to amplify the DNA. Elaborately designed DNA molecules, which have a branched structure with a complementary sticky end, can be hybridized to each other via DNA ligase, self-assembling into a 3D DNA hydrogel $^{115,116}$ (Fig. 3G, H).

Natural and synthetic polymers are frequently hybridized to compensate for the shortcomings each may possess alone. For example, copolymerization of PEG and PEG conjugated with natural polymers such as hyaluronan, ${ }^{73}$ collagen, ${ }^{74}$ and biological ligands ${ }^{117}$ enables better control over the physical and biochemical properties of natural and synthetic cellentrapping materials, respectively.

Modifications. From a structural manufacturing standpoint, the cell-entrapping technique is based on the selfassembly of materials around cells, rather than the shaping of a bulk material to a specific architecture. Therefore, modification techniques are focused more on engineering unit biomolecules for directed assembly or to induce certain functionality than on manufacturing processes. The first example is advanced hybridization of natural and synthetic materials to create a cell-responsive 3D culture environment. Here, PEG macromers are covalently conjugated with cell adhesive and proteolytic cleavage ligands such as matrix metalloproteinase (MMP) degradation sites. ${ }^{118}$ Cells cultured within this modified PEG-based hydrogel can grow and migrate deep into the matrix, creating spaces after local matrix degradation using cell-secreted MMPs. Hybridization also allows for a mild polymerization process separate from photopolymerization without generating free radicals, called a Michael-type addition reaction. In this process, gelation initiates after 2 building groups, end- functionalized macromers and bi-functionalized peptides, are mixed as cross-linkers $^{119}$ (Fig. 3I). Another method of materials engineering involves the molecular design of unit peptides to have specific functionalities. Versatile alteration of amino acid sequences in the hydrophilic peptide head groups provides specific cell-binding or cell-signaling environments for the systematic investigation of cell differentiation ${ }^{120}$ (Fig. 3J). The last example is a modification of the cellentrapping process involving a patterned multi-cellular organization instead of a random distribution of cells within 3D PEG hydrogel. Positive dielectrophoretic forces generated along a micro-patterned dielectric mask direct the 3D spatial organization of cells suspended in a PEG precursor solution because of the negative net charge of the cell membrane. After PEG photopolymerization under UV light, the cells are fixed in a desired pattern ${ }^{121}$ (Fig. 3K).

Applications. Cell-entrapment techniques have been used extensively in constructing $3 \mathrm{D}$ in vitro model systems because of distinct differences in cellular morphogenesis, function, migration, and differentiation from conventional 2D culture. For example, breast epithelial cells cultured within 3D Matrigel formed an acinus structure possessing a cellular morphology akin to that of an in vivo structure that was never observed in $2 \mathrm{D}$ culture. ${ }^{95}$ This prominent morphological change originated from 3D Matrigel characteristics that resemble those of breast epithelial ECM, such as comparable density of cell adhesion sites and growth factor receptors (Fig. 4A). The recovered 3D cellular morphology of tissue is closely related to greater viability and restoration of functionality. For instance, breast epithelial cells forming a 3D acinus structure could synthesize and secrete some milk proteins in the presence of lactogenic hormones. ${ }^{128}$ In addition, cells had considerably greater apoptotic resistance after forming a well-organized spheroid, although cells growing on a 2D monolayer or an unorganized 3D matrix are susceptible to drug-induced apoptosis ${ }^{129}$ (Fig. 4B).

These findings give insights into the importance of the 3D culture environment and suggest caution because of the pitfalls of misrepresentation in conventional 2D culture systems. One relevant example involves conventional in vitro cell migration studies. Until now, fundamental cell migration research has been performed in 2D culture models. Accumulating discrepancies between 2D models and in vivo behavior have indicated the importance of 3D models, which more accurately represent physiological environments in dimensionality, architecture, and polarity. For instance, in 2D model systems, proteolytic degradation of the matrix is regarded as a trivial cell-migration mechanism. ${ }^{130}$ In contrast, local cleavage of matrix proteins (e.g., collagen and fibrin) by MMPs is a critical event in $3 \mathrm{D}$ models because the process 


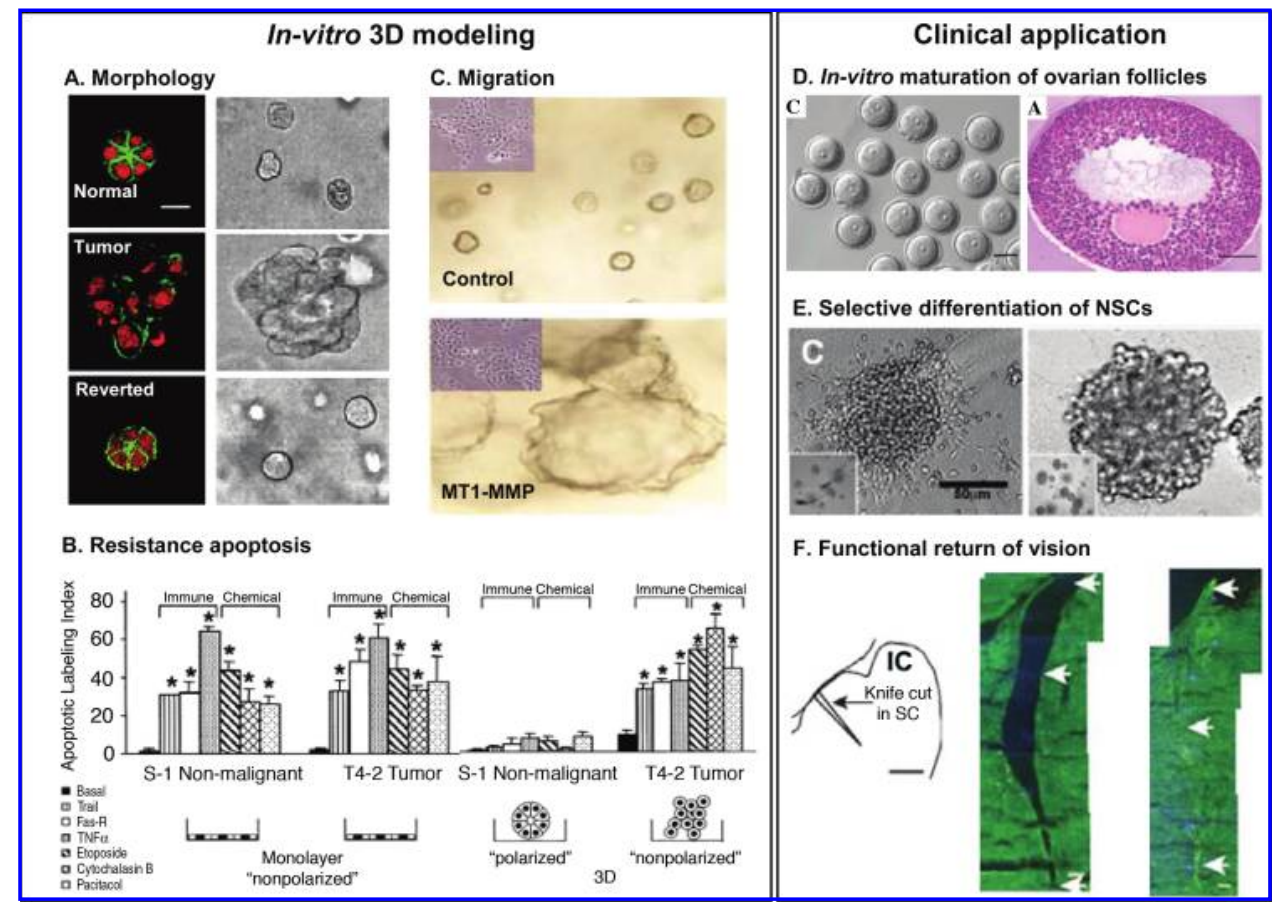

FIG. 4. Applications of 3-dimensional (3D) cell-entrapment matrices. (A) Confocal and optical images of breast epithelial cells growing in 3D Matrigel. Normal breast epithelial cells formed an acinus structure, and tumor breast epithelial cells were randomly organized, but tumor cells recovered normal morphology when cultured in $\beta 1$-integrin- and epidermal growth factor receptor-corrected Matrigel. ${ }^{140}(\mathbf{B})$ Only non-malignant cells that formed a polarized acinus structure were resistant to apoptosis. ${ }^{141}$ (C) Membrane type-1-MMP-transfected cells proliferated at a significantly faster rate than control cells under a 3D collagen gel growth environment. ${ }^{132}$ (D) Alginate-encapsulated mouse oocytes (left) and in vivo-like follicle development after 8 days of culture (right). ${ }^{135}$ (E) Neurite outgrowth from neurospheres cultured in isoleucine-lysine-valine-alanine-valine-presenting peptide gels (left) and control peptide gel (right). ${ }^{114}$ (F) Functional return of vision by peptide hydrogel matrix: schematic illustration of knife cut of the midbrain of a hamster (left), histological images of 30 days after control (middle) and peptide hydrogel-filled (right) injury section. The tissue was reconnected across the injury section. ${ }^{113}$

opens up the spaces in 3D matrices to promote cell migration. $^{26,131}$ Hotary et al. demonstrated the role of membrane type-1 (MT1) MMP in tumor cell proliferation and migration within a 3D collagen matrix. Although the 3D mesh-like structure of the ECM provides physical support for normal cells, it also acts as a physical restraint, regulating proliferation and migration of malignant cells. For that reason, tumor cells incapable of MT1-MMP synthesis could not proliferate within a $3 \mathrm{D}$ collagen matrix, although they could readily proliferate on top of a 2D gel. In contrast, MT1-MMPproducing tumor cells could proliferate and migrate in a $3 \mathrm{D}$ matrix by disrupting the surrounding matrix and acquiring extra space $^{132}$ (Fig. 4C). Cell-entrapping techniques and materials are being actively researched for clinical applications. For example, Tisseel, a commercialized cell-entrapping material, is used as a biological sealant and would-healing matrix for post-operative rehabilitation. Transplantation of microencapsulated islet cells (i.e., insulin-producing cells in the pancreas) has long been recognized as a promising cure for diabetes. ${ }^{133}$ Recently, this idea was extended to in vitro maturation of ovarian follicles. In vitro culture of alginateencapsulated follicles were shown to undergo normal development and were able to be fertilized. ${ }^{134}$ Once implanted into mice, the resulting live birthrate was greater than with $2 \mathrm{D}$ culture and was comparable with the birthrate with in vivo control oocytes. ${ }^{135}$ Moreover, the authors could systematically investigate the effects of chemical composition and mechanical stiffness during follicle development. Collagen I and RGD advanced the evolution of follicles from 2-layered secondary stages to multi-layered secondary stages. ${ }^{136} \mathrm{Ma}-$ trices with lower moduli resulted in higher-quality oocytes, and those with lower concentrations of solids resulted in better follicle development ${ }^{137}$ (Fig. 4D). In addition, nerve tissue regeneration within a $3 \mathrm{D}$ peptide hydrogel is receiving strong attention as a potential treatment for recovery from nerve tissue injury because of its excellent nano-scale physical structure, which is similar to the dimension of a neurite and the representative biochemical environment. Holmes et al. demonstrated that 3D peptide-based scaffolds supported extensive neurite development and active synapse formation from in vitro culture of primary rat neuronal cells. ${ }^{138}$ Schense et al. also reported that a fibrin-based hydrogel matrix incorporating bioactive peptides (e.g., laminin and $\mathrm{N}$-cadherin) enhanced adhesion and neurite extension of individual ganglion cells in in vitro culture. ${ }^{139}$ A peptide gel presenting the neurite-promoting epitope (isoleucine-lysine-valine-alanine- 
valine) could regulate the differentiation pathway of neural progenitor cells into neurons while suppressing astrocyte differentiation. ${ }^{114}$ Scar tissue formation has been a notorious barrier to functional recovery of injured nerve tissue; thus, selective differentiation of neuronal progenitors into neurons raises the possibility of clinical solutions to successful nerve tissue regeneration (Fig. 4E). Recently, Ellis-Behnke et al. reported the possibility of using peptide scaffolds for the regeneration of axons in mammalian visual systems. A 2mm-deep lesion was made in the optical tract of a hamster and was filled with self-assembling peptide hydrogel. The scaffold created a favorable environment for axonal penetration and closed the neural tissue gap. Axons were sufficiently regenerated and reconnected the brain with target tissue, restoring functional vision ${ }^{113}$ (Fig. 4F). Overall, cellentrapment techniques were excellent test grounds, demonstrating the importance of 3D matrix biology. These techniques also have strong potential for use in clinical applications in the near future. Cell mobility in gelling matrixes is an important challenge, limiting the range of functionalities and the replicas of ex vivo organs.

\section{Polymer processing to obtain porous $3 D$ matrices}

Techniques. Numerous polymer-processing techniques have been developed to fabricate 3D porous matrices with particular applications in tissue engineering. Specific details of each method are described extensively elsewhere. ${ }^{52,142}$ Here, we broadly assess popular polymer processing techniques that yield 3D matrices with a stochastic architecture, the structures of which we divide into fibrous and spongelike. The internal structures of the 3D matrices discussed here are highly dependent on the chosen fabrication process; thus we will specifically focus on these fabrication techniques, as well as the resultant 3D micro-scale structures.

Matrices with a fibrous structure are typically fabricated using an electrospinning process that can continuously generate micro- or nano-scale diameters of fibers with simple set-up, inexpensive handling costs, and versatile material selection. ${ }^{7}$ The benefits of a 3D fibrous matrix include a high surface-to-volume ratio and a structure similar to the $3 \mathrm{D}$ fiber network of collagen and elastin in natural ECM. A major hindrance to cell culture is that small pores among fibers considerably hamper cell migration.

All other types of matrices displaying stochastic architecture can be described as having a sponge-like structure. Sponge-like 3D substrates have a porosity and surface-tovolume ratio that is similar to or lower than those of fibrous matrices but larger pores that can significantly improve cell seeding and migration. Sponge-like fabrication techniques can be divided into 2 groups based on whether a porogen is employed. Freeze-drying and gas foaming are widely accepted methods that do not use a porogen. The freeze-drying process includes blending a solvent-polymer mixture and an appropriate volume of water to form an emulsion. The emulsion is quickly frozen in liquid nitrogen and freeze- dried, leaving behind a porous structure where water has been evaporated. ${ }^{143}$ The use of organic solvents to dissolve polymer has been recognized as a major hindrance that can be avoided with gas foaming. The gas-foaming process involves high-temperature compression molding of the polymer to form a solid disk-like structure. The structure is then exposed to a high pressure $\mathrm{CO}_{2}$ chamber for several days, during which the gas infiltrates the polymer. As the pressure is decreased, the gas escapes the polymer, leaving a porous, sponge-like structure. ${ }^{144}$ The gas-foaming process is favorable for incorporating biological molecules because no organic solvent is used. ${ }^{76}$

Solvent casting and particulate leaching are representative methods of achieving a sponge-like porous matrix with a porogen. The concept behind particulate leaching is to mix polymer and solvent with particulates that can be dissolved with a separate solvent. Generally, synthetic polymers are dissolved in an organic solvent and mixed with porogen particles. Typical porogens include salt or sugar particles, because they are insoluble in organic solvents and can be removed by exposure to liquid water. The polymer-solventparticulate mixture is then cast into a mold, and the solvent is evaporated, leaving a solid polymer-particulate construct. After exposing the construct to the particulate solvent, the remaining polymer will have a porous structure with empty cavities where the crystals resided. ${ }^{8}$ Again, using an organic solvent is a major disadvantage. An important consideration of sponge-like structures is pore interconnectivity. In porogen-based techniques, particles in a porogen are frequently fused together, by exposure to greater humidity for salt particles or by heat treatment of paraffin spheres, to improve pore interconnectivity. ${ }^{145,146}$ Gas-foaming and freezedrying processes can incorporate salts or sugar porogens in polymer solution to enhance pore interconnectivity as well as to control overall porosity. ${ }^{147,148}$

Structure. The shape and size of the mold in which it is created or cutting or punching out a structure from a larger matrix piece normally determines the macro-scale structure of 3D matrices (Fig. 5A, B). Scaffolds often have a simple cylindrical or rectangular shape. In clinical applications, a patient-specific macro-scale scaffold structure is typically achieved by using 3D molds fabricated using computerassisted fabrication methods; more detail will be discussed in the next section.

Characteristics of the micro-scale structure of fibrous 3D matrices include fiber diameter, fiber alignment, and pore size among fibers (Fig. 5C-E). Fiber diameter is sensitively affected by physical and electrical properties of polymer solution such as viscosity and conductivity. ${ }^{7}$ Fiber alignment can be achieved by modifying the design of the collector (i.e., a high-speed rotating frame $)^{149}$ or by using 2 conductive electrodes separated by an insulating gap. ${ }^{150}$ Pore size can be controlled by co-spinning of polymer solutions with different degradation kinetics, such as PCL and gelatin, ${ }^{151}$ or by using multi-layer spinning to create $3 \mathrm{D}$ matrices having micro- 


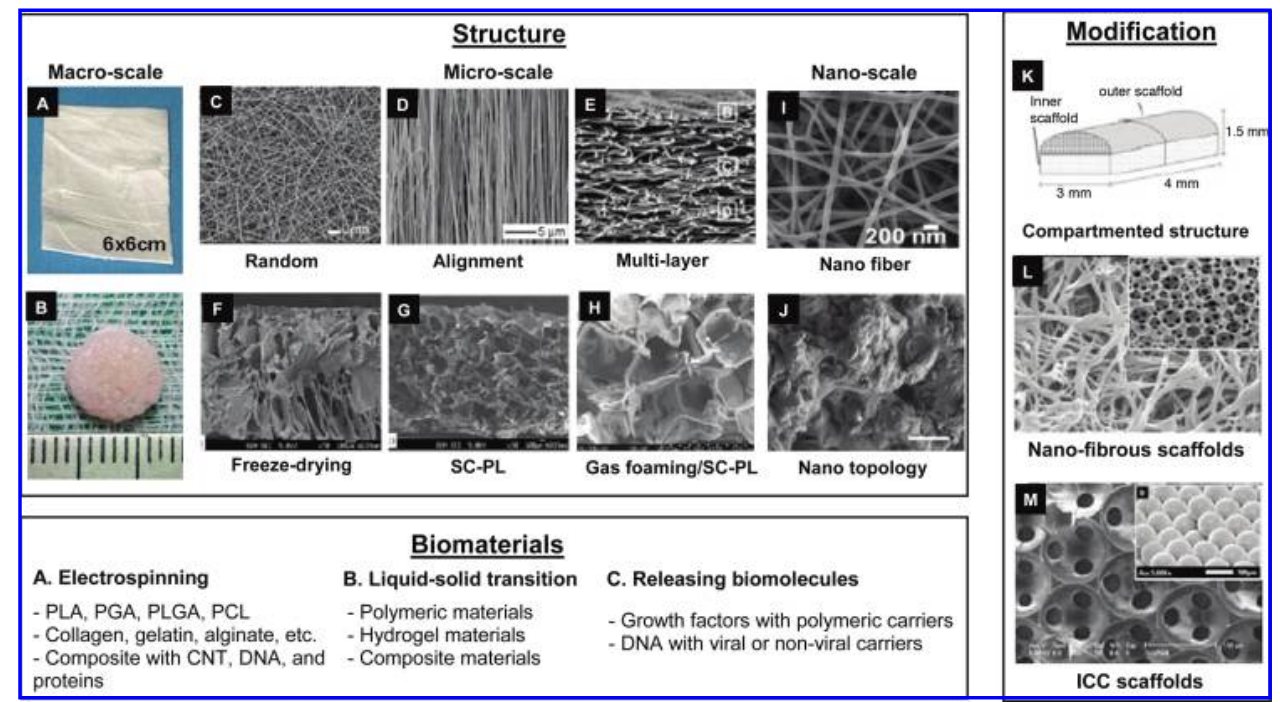

FIG. 5. Overview of polymer processing techniques for obtaining porous scaffolds. Macro-scale structure of (A) an electrospun fibrous mesh sheet and (B) a poly(lactic-co-glycolic acid) scaffold. ${ }^{160}$ Micro-scale fibrous structures: $(\mathbf{C}),{ }^{161}$ (D) ${ }^{162}$ (E) ${ }^{152}$ and micro-scale sponge-like structures: $(\mathbf{F}),{ }^{163}(\mathbf{G}),{ }^{163}(\mathbf{H}) .{ }^{147}$ Nano-scale (I) alginate-based nanofibers ${ }^{164}$ and (J) surface topology after sodium hydroxide treatment. ${ }^{165}$ Modification of polymer processing techniques: $(\mathbf{K})$ compartmented scaffold structures, ${ }^{155}(\mathbf{L})$ nano-fibrous scaffolds, ${ }^{48}$ and (M) inverted colloidal crystal scaffolds. ${ }^{57}$

fiber ( $\sim 5$ - $\mu$ m diameter) and nano-fiber $(\sim 600$-nm diameter $)$ layers. ${ }^{152}$ Here, by reducing fiber diameter to the nano- scale, nano-scale structural features can be achieved (Fig. 5I).

The micro-scale structural characteristics of sponge-like 3D matrices include porosity, pore interconnectivity, pore size and geometry, and pore-size distribution (Fig. 5F-H). The internal architecture of 3D sponge-like matrices manufactured without a porogen is entirely dependent on the fabrication process. Although relatively thick matrices are achievable, these matrices frequently have uncontrolled architectures and isolated pores that limit cell-cell interactions and full tissue infiltration. A porogen-based technique can yield a more controllable and interconnected 3D microstructure, but the thickness is limited to less than $2 \mathrm{~mm} .{ }^{153} \mathrm{~A}$ moderate level of nano-scale structure can be controlled using post-fabrication surface treatments ${ }^{49,57}$ (Fig. 5J).

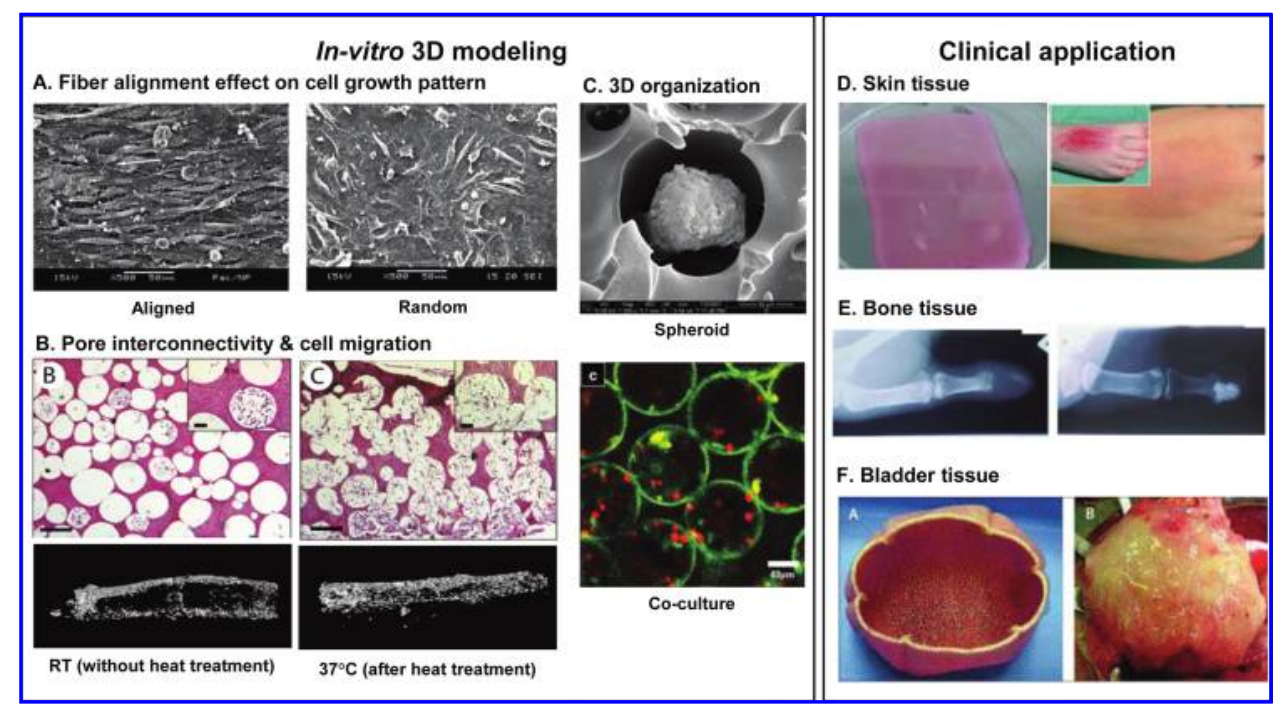

FIG. 6. Applications of polymeric scaffolds: (A) fiber alignment directed the growth pattern of rabbit fibroblasts. ${ }^{168}$ (B) Improved pore interconnectivity after heat treatment enhanced cell migration efficiency deeper into the scaffold. Histological section (upper) and micro computed tomography (lower) images of human mesenchymal stem cells on silk fibroin scaffolds. ${ }^{170}$ (C) Three-dimensional cellular organization: (top) spheroid formation in spherical pore, (bottom) co-culture of floating and adherent cells in the same pore. ${ }^{57}$ Clinical usage of scaffolds in (D) skin tissue, ${ }^{98}(\mathbf{E})$ bone tissue, ${ }^{30}$ and (F) bladder tissue regeneration..$^{29}$ 
The overall stochastic structure of this type of scaffold contributes to the simplicity of its preparation but may not be beneficial in terms of its mechanical and mass transport properties. Difficulties also exist with in silico modeling of biological processes in it and computer-assisted analysis of the $3 \mathrm{D}$ images.

Biomaterials. The electrospinning process employs a diverse set of synthetic polymers. Combinations of synthetic and natural materials (e.g., collagen, alginate, chitin, and silk) and functional nano-materials (e.g., CNTs, DNA, hydroxyapatites, and proteins) are also used as jetting materials. Concurrent spinning of different materials on the same collector can create scaffolds of multiple materials. ${ }^{4,151}$

Because of the absence of organic solvent, many biologically active molecules (e.g., growth factors ${ }^{76}$ and DNA) ${ }^{154}$ can be incorporated into PLGA-based bulk materials for scaffolds fabricated using gas foaming. In the solventcasting particulate leaching technique, salt crystals, sugar spheres, and paraffin spheres are commonly used as porogen particles. Virtually any material that undergoes liquid to solid transition can be used as a bulk material, but synthetic polymers, particularly PLA, PGA, and their copolymers, are commonly used. Many functional nano-materials and biological molecules can be incorporated with bulk materials and combined with carrier systems to protect biological molecules from organic solvents.

Still, considering these methods of scaffold preparation, we see an important problem that needs to be solved in the preparation of similar matrices with a high content of biodegradable inorganic material such as hydroxyapatite. This is important for bone implants and manufacturing materials with the stiffness necessary for bone engineering. Hybrid organic-inorganic materials with a high content of inorganic material in the composite similar to that observed in bone are difficult to make starting from polymer solutions.

Modification. The flexibility of polymer processing techniques enables the construction of 3D structures for specific applications. Teng et al. developed a PLGA-based 3D matrix with 2 distinct structures to treat spinal cord injuries. ${ }^{155}$ The inner and outer regions of the 3D matrix were fabricated separately and then combined. The inner region, fabricated using a salt-leaching process (250- to 500- $\mu$ m diameter) and consisting of larger pores, was seeded with neural stem cells (NSCs). The outer region, with smaller $(<50-\mu$ m diameter $)$ and axially oriented pores, was prepared using a solid-liquid phase-separation technique. Axially oriented smaller pores were designed to guide axonal extension and to allow proper fluid transport while inhibiting ingrowth of scar tissue. The NSC-seeded multi-component scaffolds were implanted into a rat for 1 year. Rats implanted with the scaffolds with NSCs showed significantly better functional recovery than lesion and cell-only control groups ${ }^{155}$ (Fig. 5K).

Combining polymer processing techniques makes it possible to build 3D matrices with multi-scale structural prop- erties. Ma et al. created nano-fibrous scaffolds with nanoscale $(50-500 \mathrm{~nm})$ fibrous surface textures on a micro-scale pore surface by combining the particulate leaching technique and the phase-separation process. ${ }^{43}$ A homogeneous mixture of PLLA and an organic solvent infiltrated into paraffin- or sugar-based porogen undergoes a polymer-rich and polymerlean phase separation process below a critical temperature $\left(-70^{\circ} \mathrm{C}\right)$. When freeze-dried, the polymer-lean phase ends, and the polymer-rich phase undergoes a crystallization process, generating a randomly organized nano-scale fibrous structure. The nano-scale fibrous surface morphology was an analogue of type I collagen fibrils on natural ECM, and the micro-scale open porous structure overcame the cell-seeding and cell-migration limitation of the electrospun matrix. ${ }^{156}$ Combined with a modified SFF process, which will be discussed in the next section, the final scaffolds could have controlled macro- and micro-scale 3D structures, as well as random nano-scale structures, on the walls of the matrix ${ }^{157}$ (Fig. 5L).

Even though porogen-based fabrication techniques improved the controllability of 3D microstructure, it was very limited to reproduce the same structure. Recently, ICC scaffolds were introduced, significantly improving the controllability and consistency of micro-scale 3D structures without any expensive equipment or computer-assisted tools. ${ }^{37}$ A colloidal crystal, a highly packed 3D assembly of uniformly sized microspheres (10- to 500- $\mu$ m diameter) was used as a template. Matrix materials were infiltrated into the colloidal crystal, and when the microspheres were removed, the resulting ICC scaffolds contained a highly ordered and interconnected array of identically sized spherical pores. Pore and channel sizes could be adjusted easily by changing the microsphere size. ${ }^{158}$ Moreover, the micro-scale architecture, hexagonally arranged spherical cavities, and overall matrix porosity $(\sim 74 \%)$, remained identical with high reproducibility. Hydrogels are frequently used as scaffolding material for ICC scaffolds. Because of their structural uniformity and consistency, as well as their excellent transparency, ICC scaffolds are a valuable tool for in vitro cell studies $^{57,159}$ (Fig. 5M).

Application. Understanding cell responses to 3D microstructures is an important motive for constructing in vitro tissue models. In fibrous structures, fiber diameter and alignment are key parameters. Smaller fiber diameter tends to result in greater protein adsorption, subsequently enhancing cell adhesion. For example, a nano-scale fibrous surface supported more serum protein adsorption than solid-wall scaffolds and promoted almost twice the amount of fibroblast adhesion. ${ }^{166}$ Fiber diameters also affect cell proliferation and differentiation. For instance, chondrocytes showed wellspread and round-shaped morphologies on micro-fibrous and nano-fibrous scaffolds, respectively. Additionally, nanofibrous matrices displayed a higher proliferation rate and higher level of protein synthesis. ${ }^{167}$ Regarding fiber alignment, regularly aligned nano-fibrous collagen scaffolds 
showed less initial cell adhesion but greater cell proliferation because of more-stable cell attachment than in a control structure with randomly oriented fibers ${ }^{168}$ (Fig. 6A). Although detailed mechanisms require further research, it is apparent that the resolution and pattern of fibrous structures modulate various cellular functions. In sponge-like structures, pore size and pore interconnectivity are critical considerations for proper cell seeding and growth. Pore diameters smaller than the size of cells $(10-100 \mu \mathrm{m})$ significantly hinder appropriate cell seeding and migration, ${ }^{37}$ but pore diameters that are too large prevent appropriate ingrowth of cells. For example, scaffolds with pores larger than $500 \mu \mathrm{m}$ induced undesired fibroblastic tissue formation by osteoblasts rather than bone tissue development. ${ }^{169}$ Pore interconnectivity is essential for proper cell migration. For example, 3D matrices with similar pore sizes but different levels of pore interconnectivity made using heat-treatment of porogen caused significant differences in the surface:volume ratio for cell growth. Scaffolds with higher levels of pore interconnectivity promoted cell migration distances, whereas the lack of interconnecting channels in control scaffolds limited cell migration, and most cells were observed near the surface $^{170}$ (Fig. 6B). Currently, the optimum range of pore and channel size for each cell type is unknown. The development of 3D matrices with highly controllable micro-scale structure will contribute to answering these questions. The knowledge gained from studies on 3D matrix models currently is much more limited than that gained from $2 \mathrm{D}$ culture models ${ }^{171}$ because of the lack of structural controllability on the dimensions of cells.

Micro-scale scaffold architecture is crucial in guiding 3D cellular organization and the subsequent recovery of tissue functions. For example, primary hepatocytes cultured in 3D matrices formed spheroids (3-dimensionally organized cell aggregate) and recovered typical morphological features in the liver. As a result, cell viability was significantly better and tissue-specific functions, such as albumin secretion and drug metabolism, were maintained in a long-term in vitro culture. ${ }^{23,172}$ Micro-scale spherical pore geometry was better than other pore shapes for facilitating the spheroid formation process. Recently, Fischbach et al. reported tumor-like tissue formation from various types of carcinoma cells within sponge-like PLGA scaffolds in vitro. The microenvironments within the scaffolds recreated characteristics representative of tumors in vivo. Engineered tumors within the scaffolds not only recovered tumor-like morphology better than 2D carcinoma cell cultures, but also recuperated tumor functions better, such as enhanced angiogenic capability and reduced sensitivity to chemotherapy. ${ }^{173}$

The internal architecture of scaffolds will need to be designed to allow specific 3D configurations of cell-cell interactions. For example, in bone marrow and thymus, extensive cell-cell interactions between floating hematopoietic stem cells (HSCs) and adherent stromal cells are essential for the proper development of immune cells. ${ }^{174}$ The scaffolds in this application are required to support both types of cells within a confined space, which is considerably limited on a 2D substrate. Sponge-like scaffolds were used in a co-culture of murine thymic stromal cells with human HSCs. Sufficient surface area supported stromal cell growth, and a large portion of empty space allowed for movement of floating cells in the scaffolds. This 3D co-culture environment enabled intimate cell-cell interactions and significantly promoted HSC differentiation into T-lymphocytes. ${ }^{175}$ Recently, the controlled 3D configuration of suspension and adherent cell interactions was demonstrated within a highly organized and uniform micro-environment of ICC scaffolds. Suspension cells temporally entrapped in a pore can undergo extensive interactions with adherent cells growing on the pore surface ${ }^{57}$ (Fig. 6C).

In vivo testing of scaffolds in animals showed the possibility of specific tissue regeneration. The most successful clinical application is skin tissue. Decellularized human- or animal-derived collagen 3D matrices are commonly used for regeneration of skin tissue ${ }^{98}$ (Fig. 6D). The second most successful clinical application of scaffolds is in bone tissue engineering. Sponge-like, hydroxyapatite composite scaffolds are commonly used, and their macro-scale structure is tailored using cutting or computer-assisted fabrication ${ }^{30}$ (Fig. 6E). Tissue-engineered bone has advantages over conventional autologous or cadaveric bone grafts or synthetic materials (e.g., flexibility to mimic anatomic structure, no risk of disease transfection, minimal donor site morbidity). Other tissues also have been regenerated on scaffolds. For example, human bladder tissue was engineered on collagenPLGA scaffolds after culturing the patient's derived urothelial and muscle cells for 7 weeks. Engineered bladder tissues were implanted and displayed preserved renal function. The macro-structure of scaffolds was customized to assess the size, shape, and volume of the pelvic cavity of each patient. Three-dimensional CT imaging and computerassisted fabrication techniques were used, which will be discussed in the next $\operatorname{section}^{29}$ (Fig. 6F).

\section{Computer-assisted fabrication}

Technique. Computer-assisted fabrication has several advantages over non-computer-assisted fabrication techniques. Primarily, scaffolds can be manufactured as customized multi-scale 3D structures, which are essential for clinical applicability. Additionally, manufacturing is timeeffective and economical. Efficient manufacture is essential in clinical applications, in which the window for implantation is often critical. Currently, SFF fabrication is the most popular and powerful technique to construct 3D matrices with this level of design and efficiency. ${ }^{176}$ The overall procedure of SFF fabrication consists of up to 3 steps: acquiring 2D image slices of a target specimen from CT, MRI, quantitative ultrasound, or other nondestructive imaging methods; designing micro-scale internal architecture and reconstructing the macro-scale $3 \mathrm{D}$ matrix shape using $\mathrm{CAD}$ or other software; and fabrication of the 3D matrix using 
automated layer-by-layer construction with SFF processes 9 (Fig. 7A-C). The 3 main types of SFF processing techniques are laser-based, nozzle-based, and printer-based systems. (Fig. 7D) Laser-based techniques include photopolymerization and selective laser sintering (SLS). Photopolymerization requires the exposure of liquid monomer solution to a UV beam, which polymerizes the exposed layer. The specimen, which is sitting on an elevator, is then lowered into a vat of monomer to coat the polymerized layer; this new monomer layer is then exposed to the UV laser to build the next layer. ${ }^{177}$ SLS uses a laser beam to scan a powder bed, raising the temperature of the exposed area and sintering the powder into a fused solid. ${ }^{178}$ Fused deposition modeling (FDM), a nozzle-based technique, extrudes molten scaffold material through a nozzle as it moves in the $x-y$ plane, directly building a layer of the scaffold with each sweep across its cross-section. ${ }^{35}$ Another emerging extrusion technique is robocasting, which deposits a slurry of ceramic powder, a volatile solvent, and chemical modifiers through a syringe. ${ }^{179}$ After a layer is deposited, it solidifies as the solvent evaporates, allowing for deposition of the next layer. After all layers are deposited, the structure is sintered. Threedimensional printing is a process that deposits a liquid binder solution onto a powder bed using an ink jet printer. The binder solution causes powder particles to join and harden, forming the 3D matrix in layers. ${ }^{180}$

Recently, MAP, an advanced form of micro-fabrication technique, has been used in 3D matrix fabrication because of its significantly enhanced structural resolution and flexibility of architecture design. Here, an ultra-fast multiphotongenerating laser beam is focused on a microscope objective. It creates local excitation within the focal volume of the beam, providing precise polymerization in the confined space. ${ }^{104}$ By scanning the focal point in a pre-designed pattern, a complex 3D matrix can be constructed. ${ }^{181,182}$

Structure. 3D matrix structural design for computerassisted fabrication can be based on homogenization theory or CAD to design unit cells with various materials, porosities, and internal architectures. These unit cells are then combined for a desired overall architecture. This determined architecture is then used as instructions for the 3D printing of a matrix. These methods are discussed further below in the context of using SFF matrices as modeling tools.

An important potential for computer-assisted manufacturing that sets it apart from other manufacturing techniques is the ability to construct matrices with specific macro-scale architecture (shaped for a wound site). Still, the ability to build a matrix layer by layer in any 3D configuration is limited in many manufacturing techniques. For example, photopolymerization does not use a support material, which limits the possible shapes in which the matrices can be constructed. ${ }^{176}$ FDM uses a support material, which allows for building in any direction and fabricating almost any shape matrix. For many materials, control over macroscale structures is limited.
Micro-scale features can be moderately controlled in that many geometries can be constructed, allowing for the design of numerous internal architectures (Fig. 7E-G). Still, the lack of support material also hinders the fabrication of certain cavity shapes, such as spherical or other rounded surfaces. Additionally, control of internal structure on the scale of a few hundred microns and smaller is limited because of inherent constraints of manufacturing parts (e.g., laser spot size, nozzle diameter, degree of position controller handing), as well as material constraints (e.g., particle size of powders). Currently, the minimum feature size is restricted to approximately 100 to $500 \mu \mathrm{m}$, depending on the fabrication process selected. ${ }^{176,186,187}$

Matrices manufactured using SFF do not possess distinct nano-scale features, because the minimum resolution of most fabrication techniques is larger than $100 \mu \mathrm{m} .{ }^{9}$. Most methods of introducing nano-scale features to SFF matrices are post-fabrication processes. Limited nano-porosity can be introduced into hydroxyapatite scaffolds by varying the sintering temperature. Russias et al. demonstrated the precipitation of hydroxyapatite nanoparticles onto the surface of robocast printed PLLA/bioglass scaffolds. ${ }^{188}$

MAP provides an excellent alternative to overcome the limitations of the aforementioned methods of computerassisted fabrication. Three-dimensional structures constructed using MAP provide excellent control over micro- and nanoscale, although the $3 \mathrm{D}$ matrix is dependent on a $2 \mathrm{D}$ mold. ${ }^{181}$ With current techniques, the minimum resolution of one volume element exposed using multi-photon absorption (i.e. a voxel) is $100 \mathrm{~nm} .^{104}$ Although MAP has been less investigated than SFF as a 3D cell culture substrate, its excellent controllability of structure holds great potential, particularly for the application of in vitro 3D model tissue construction (Fig. 7H).

Biomaterials. Customized hard tissue engineering has traditionally been the most promising application of SFF 3D matrices; therefore, the mechanical properties and biodegradability of bulk materials are stressed in these scaffold designs. Functional materials, such as calcium phosphate particles ${ }^{189}$ and hydroxyapatite, ${ }^{190}$ are often mixed with basic bulk materials to mimic bone ECM composition. These composite materials often improve the mechanical properties of bulk material. ${ }^{189}$ Surface properties have been emphasized to a lesser degree because of limited material selection and feature size control. Typically, the selected fabrication process determines the choice of applicable materials. For example, nozzle-based techniques are limited to synthetic polymers because the material is melted before extrusion. Here, PCL is extensively used in a FDM system because of its low glass-transition temperature and high decomposition temperature. ${ }^{191}$ Printing-based processes, such as 3D printing, use mainly PLA, PGA, and PLGA as basic building materials and chloroform as a binding solution. ${ }^{180}$ The use of organic solvents is a problem with this method. For photopolymerization, the selection of precur- 


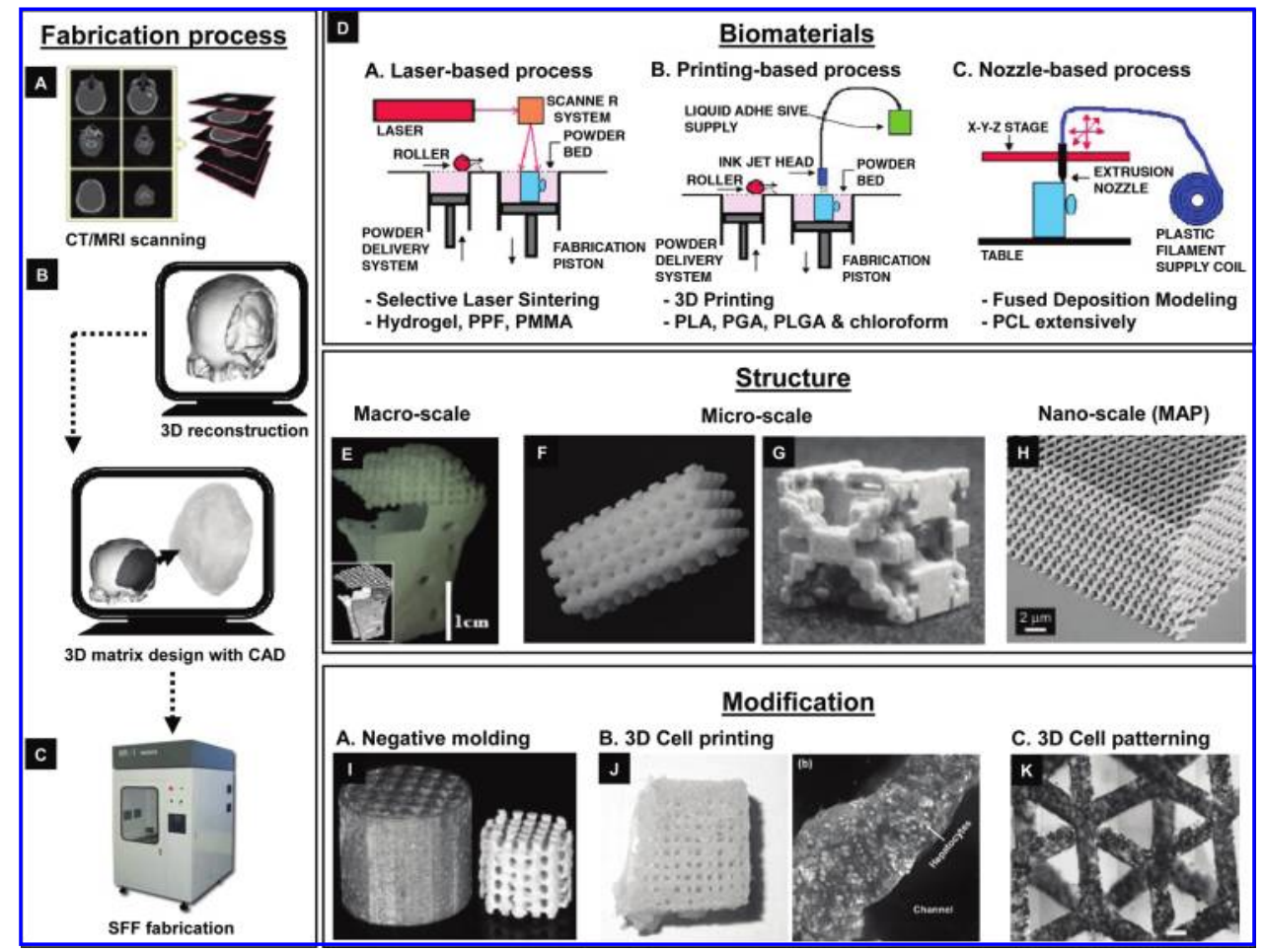

FIG. 7. Overview of computer-assisted 3-dimensional (3D) matrix fabrication techniques. (A) Two-dimensional slice scanning with micro computed tomography or magnetic resonance imaging image from http://www.custard.org/ andrew/visualization/introduction/ (B) Three-dimensional image reconstruction and 3D matrix design with CAD software. (C) Three-dimensional matrix fabrication using solid free-form (SFF) equipment. (D) Representative SFF fabrication processes, images from http://hime.att.net/ castleisland/. (E) Macro-scale scaffold design manufacture using selective laser sintering. ${ }^{199}$ Micro-scale structures fabricated using SFF processes: (F) selective laser sintering ${ }^{36}$ and (G) 3 D printing. ${ }^{35}$ (H) Nano-scale structure prepared using multi-photon absorption polymerization. ${ }^{181}$ (I) Indirect fabrication using negative molding: wax mold (left) and cast ceramic mold (right). ${ }^{194}$ (J) Three-dimensional cell printing of hepatocytes with gelatin. ${ }^{196}(\mathbf{K})$ Three-dimensional cell patterning of hepatocytes in polyethylene glycol hydrogel. ${ }^{198}$

sor solution is limited to materials that can undergo UV polymerization (e.g. hydrogels and PPF-based polymeric materials). ${ }^{192}$ SLS employs powdered materials such as ultra-high-molecular-weight polyethylene ${ }^{193}$ and PCL. ${ }^{36}$ MAP uses acrylate polymers that can undergo radical polymerization, such as PEG-diacrylate, and other materials including siloxanes, epoxy resins, and organic-inorganic hybrids. ${ }^{104}$

Modifications. Limited material selection and lack of submicron-scale structural resolution are the major shortcomings of SFF techniques. Indirect SFF was developed to

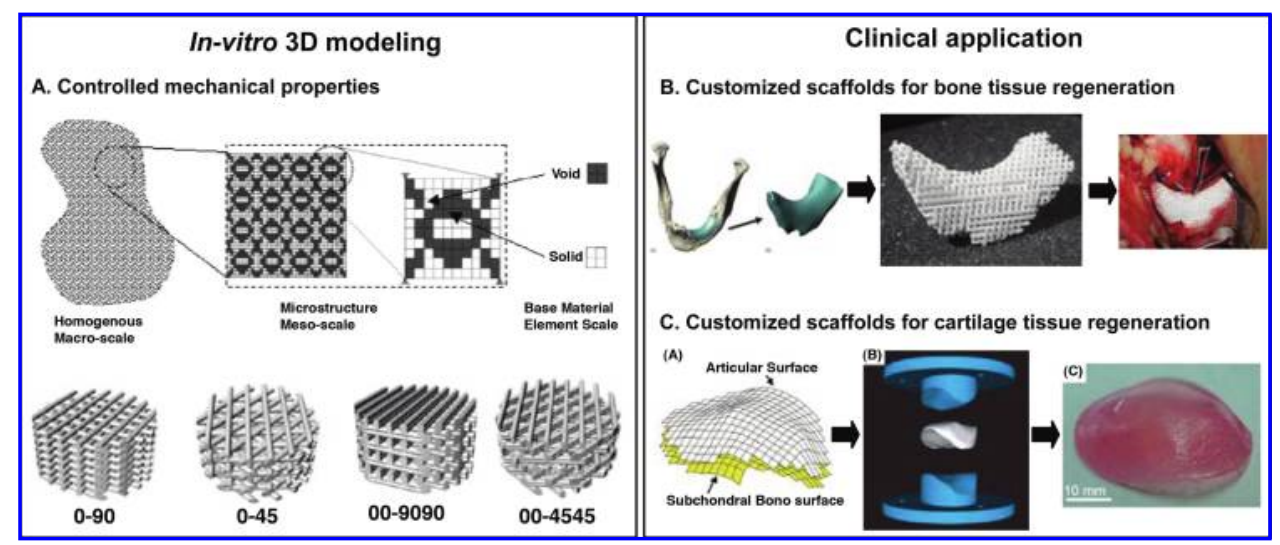

FIG. 8. Applications of 3-dimensional matrices fabricated using computer-assisted techniques. (A) Top: examples of multiple scales of unit cells. ${ }^{35}$ Bottom: Examples of multiple physical unit designs with different geometries. ${ }^{200}$ Clinical applications for (B) bone tissue $^{31}$ and $(\mathbf{C})$ cartilage tissue regeneration. ${ }^{201}$ 
alleviate these restrictions. ${ }^{194}$ The original SFF matrix is used as a negative mold to construct a $3 \mathrm{D}$ structure with a broader range of materials. Wax is commonly used as a molding material because 2 types of wax, one for support and one for the mold, can be directly printed and easily removed after casting the desired matrix material. Various polymeric materials (e.g., PPF, PLA, and PLGA) and their composites with ceramics have been used as casting materials. Additional processing of secondary materials, such as phase separation of PLLA, can generate sub-micron-level structures $^{157}$ (Fig. 7I). A negative wax mold was fabricated using 3D printing, and PLLA was cast into the mold before phase separation at $-20^{\circ} \mathrm{C}$ and dissolving the wax mold. This resulted in a nano-fibrous structure on the walls of the matrix that increased proliferation and mineralization of preosteoblastic cells. $^{157}$

Three-dimensional cell printing is an interesting derivation of the SFF process used to construct a 3D cell-matrix hybrid structure. With most scaffolds, the method of seeding cells onto scaffolds after fabrication can lead to limited 3D cell distribution and depth. A regular ink-jet printer or a SFF robotic platform is remodeled for use in $3 \mathrm{D}$ cell printing. A cell suspension is mixed into in situ cross-linkable hydrogels (e.g., gelatin, agarose, alginate gel) in a cartridge and then printed following a programmed 3D pattern. As a result, a 3D cell-matrix hybrid structure is constructed. ${ }^{195}$ Cell viability as high as $90 \%$ indicates that the ink-jet process conditions are not harsh enough to cause severe cytotoxicity. ${ }^{196,197}$ This 3D cell matrix with a spatially well-organized structure can potentially accelerate the organization of cells into a functional tissue (Fig. 7J).

Another way to build a 3D cell-matrix hybrid structure is $3 \mathrm{D}$ cell patterning. Instead of a typical SFF process, a modified photolithographic technique is used to build a patterned 3D cell-matrix construct. A mixture of cells and PEG-hydrogel precursor solution is deposited on a 2D surface, and a mask is placed on top so that only the unmasked area polymerizes under UV light. Multiple layers of a 3D hydrogel matrix can be layered atop previous layers. This method also significantly improves the homogeneity of cell distribution within a 3D matrix. Tsang et al. demonstrated a 3D hepatic tissue model constructed using this additive photo patterning technique, controlling the matrix architecture and optimizing hydrogel chemistry to attain high cell viability and liver-specific functions. ${ }^{198}$ Currently, localized cell seeding and spatially organized co-cultures are areas of active research (Fig. 7K).

Applications. The flexibility of micro-scale internal architecture design is useful for finding optimal structural features, including geometries, porosities, and pore shapes and sizes. This capability has been used particularly for optimizing mechanical properties. As implanted scaffolds are subjected to a dramatically different level of dynamic mechanical stresses, differing according to tissue type and location, it is important to balance appropriate mechanical strength for that tissue with necessary permeability for optimal growth conditions. Computer-assisted fabrication methods can be used to design optimal properties into scaffolds. For mechanical properties, this is often done at the computational stage. Homogenization theory uses finite element methods (considering the entire volume as accumulation of unit volume) at multiple scales to approximate mechanical properties of the replaced tissue; for example, it can be used to map the properties at different sites of bone. Next, a library of unit cells can be designed with various materials, porosities, and internal architectures that can then be analyzed to characterize their mechanical properties, which can be compared with those of the target tissue. Unit cells possessing the desired mechanical properties are further evaluated to determine whether the geometry, architecture, and porosity will be sufficient for implantation. The design can be further optimized, for example, by using a unit cell design containing channels to ensure complete interconnectivity throughout the scaffold. ${ }^{35}$ After the optimization, the chosen unit cells are finally integrated into the desired shape of tissue and manufactured ${ }^{9,183-185}$ (Fig. 8A).

Computer-assisted fabrication methods have also been used to study pore geometry and architecture influences on dynamic mechanical properties. Moroni et al. demonstrated that elastic properties of scaffolds could be modulated using internal structure design. ${ }^{200}$ They used FDM to build scaffolds with controlled fiber diameter, fiber spacing, layer thickness, and configuration of the deposited fibers. With greater porosity, elastic properties (dynamic stiffness and equilibrium modulus) decreased, but viscous parameters (damping factor and creep unrecovered strain) were enhanced (Fig. 8A).

The capability of large-scale manufacturing of consistent micro-scale 3D structure is another compelling advantage, because using batches of identical scaffolds removes 3D structure as an experimental variable. Ultimately, computerinstructed scaffold manufacturing processes can remove scaffold-to-scaffold variability and standardize in vitro models. No significant research has been conducted in this direction, but these applications should be more actively pursued for applications such as in vitro drug screening.

The most promising clinical application of SFF scaffolds is bone and cartilage tissue engineering, because mechanical integrity and anatomical shape are especially important with these tissues. Bone and cartilage tissue regeneration within SFF scaffolds has been demonstrated multiple times in vivo with animal models. Cesarano et al. reported human clinical tests of SFF scaffolds for bone tissue regeneration. ${ }^{31}$ The group developed a robocast hydroxyapatite matrix customized to fit an area of bone loss to reconstruct a human mandible. A CT scan of a patient's mandible was used to create a CAD model of an implant. The microstructure of the implant, which is unlikely to be generic for all scaffolds with similar anatomic locations, was designed to accom- 
modate vascular and bone ingrowth. An image technician and a surgeon worked together to develop the scaffold macro-structure to fit an individual patient, considering the locations of nerves, surface boundaries, and surfaces to accommodate potential dental implants. As one of the first clinical examples of a customized SFF implant, many important aspects of design and fabrication were stressed. For example, the surgery brought to attention the time limits of scaffold fabrication in a clinical situation, in that a scaffold must be customized and prepared for implantation within several days ${ }^{31}$ (Fig. 8B).

Customized macro-scale 3D structures also can be prepared using anatomically designed mold structures or postfabrication processes. These methods enable control over macro-scale structures of cell-entrapping matrices and polymeric scaffolds. For example, Hung et al. demonstrated anatomically shaped osteochondral constructs for articular cartilage repair using chondrocyte-seeded agarose gels. They designed anatomic molds based on joint-specific surface topography data derived from stereophotogrammetry. The anatomic molds represented the specified articular topography of the articular cartilage surface and subchondroal bone surface. The gap between the molds defined the thickness of the scaffolds. By pouring chondrocyte-laden agarose between the molding surfaces and allowing the construct to gel, anatomically shaped patellar gel constructs were created ${ }^{201}$ (Fig. 8C).

\section{FUTURE DIRECTIONS IN THE NEXT DECADE}

Three-dimensional scaffolds represent fundamentally important steps in the development of biomedical engineering, which has already generated much success but also is presented with substantial new challenges. ${ }^{202}$ The next trend in 3D cell culture should involve escaping from a largely empirical approach to a more systematic methodology. This requires developing advanced 3D-matrix fabrication techniques coupled with biomaterial engineering. Although current production techniques are valuable within a limited range of resolutions, future fabrication methods must interlace multiple-scale structures with exceptional controllability. Chemistry and engineered functionalities of biomaterials also need to be controlled further for an enhanced systematic approach; this can also be accomplished using the hybridization of manufacturing techniques and materials. For example, cell-entrapping hydrogels coupled to solid scaffolds regenerated functional cartilage by taking advantage of the improved compositional and mechanical properties of each type of 3D matrix..$^{97,203}$

At the same time, efforts must be made to standardize 3D matrices. Even though distinct advantages of 3D culture have been demonstrated, 3D cell culture is not as widely accepted in research fields as 2D culture, most likely because there is a large deviation within 3D matrix structures and compositions. Inconsistencies between matrices prevent reproducible experimental data and proper systematic analysis. Another practical reason inhibiting their wide use is the high price of $3 \mathrm{D}$ matrices, which limits the feasibility of large-scale experiments. To compensate for these challenges, the standardization of 3D matrices, along with massproduction manufacturing processes, will enable researchers to take full advantage of $3 \mathrm{D}$ cell culture matrix potential.

A clear understanding of the limitations and opportunities of $3 \mathrm{D}$ cell culture provides a guide to the feasibility of such a technology. Vascularization, for example, is the capstone in large-scale tissue-engineering applications, although obtaining vascularized tissues presents difficulties for in vitro 3D culture. Fortunately, many in vitro cell culture applications do not require vascularization because the goal is to produce a functional unit tissue rather than bulk tissue for implantation. The development of standardized in vitro 3D tissue models can be used in screening new drug compounds for toxicity and efficacy testing, reducing the need for animal and human clinical trials. Because liver toxicity causes most failures in human clinical testing of new drug compounds, ${ }^{204}$ testing pharmacological agents on functional liver tissues is an active area of research. The system will significantly improve the efficiency of the current drug discovery process. In vitro human skin tissue, the most successfully reconstructed human tissue, has been used to test a skin tissue barrier function of pharmaceutical cosmetic compounds. ${ }^{205}$ Currently, two validated commercial skin model tissues, Episkin and EpiDerm, are approved in the United States and Europe for in vitro skin corrosivity testing. ${ }^{206}$ Additionally, in vitro model systems have great potential for ex vivo culture of primary cells, particularly human stem cells. The majority of stem cell research has been performed in animal models because of the complex natural microenvironment of stem cells, called stem cell niches. ${ }^{3,174}$ There is strong motivation to construct human stem cell niches in vitro because of the ethics behind using the human body as a model testing system. Faithfully reconstructed in vitro stem cell niches will provide a deep understanding of human stem cell biology and elevate its clinical potentials. For example, in vitro expansion of human hematopoietic progenitor cells, without loss of mitotic or differentiation capacity, has the potential to supply a large quantity of nascent stem cells to bone marrow transplant patients, thereby improving the clinical success of this risky stem cell procedure.

Although there has been success in engineering human skin and bone tissue, tissue engineering for clinical applications is widely regarded as the ultimate long-term goal. To accelerate this application, extensive in vitro and in vivo animal testing of 3D scaffolds is required. The accumulated knowledge should then be properly translated into designing 3D matrices for the most efficient clinical uses. As a practical point, intimate communication between bioengineers and surgeons is necessary to ensure the success of these 
devices with patients. Bioengineers have developed a case for how the 3D micro-structure, mechanical properties, biodegradation, and vascularization are important issues related to engineering these scaffolds. Rapid fabrication of patient-specific scaffolds is just as important for the surgeons who perform implantation of engineered tissues.

Concurrent with the improvement of 3D cell culture matrices, the development of the following subsidiary technologies will maximize their practical use. (1) Cell seeding methods need be improved in order to deliver a precise number of cells into a 3D matrix with a homogeneous distribution. This is critical because variation in cell numbers hampers systematic comparison of scaffoldto-scaffold experimental results. (2) The current medium change protocols should be reconsidered, because a sudden change of medium composition disturbs pre-existing soluble signaling molecule concentration and gradients. (3) Techniques for applying external stimuli such as mechanical stress or electrical excitation to 3D matrices should be explored to better mimic the in vivo physical and electrical environment. (4) Current analytic methods of cellular processes in 3D must be improved, including confocal and micro-CT image analysis. These improvements will increase the effect of 3D matrices and accelerate the penetration of their use in different fields. (5) In addition to the above, the development of a unique set of assay techniques for the determination of biological performance and differences between real and cultured tissues is of paramount importance.

\section{CONCLUSIONS}

The motivation to mimic the $3 \mathrm{D}$ structure and composition of natural cellular environments has driven the rapid development of materials and fabrication techniques. In the current state of 3D cell culture, where materials and fabrication techniques and their modifications are constantly being developed, agreement on the ideal 3D culture conditions for any one cell or tissue type is still lacking. Thus, the acceptance of 3D cell culture in research fields is not as widespread as that of $2 \mathrm{D}$ culture. Still, the general consensus on the importance and necessity of 3D cell culture matrices in modern cell and tissue biology and engineering has been corroborated with continuously reported advantages of 3D culture over 2D culture. To use 3D cell culture and obtain meaningful data, a multi-disciplinary approach involving biologists, materials engineers, computer engineers, biomedical engineers, and surgeons should be taken in designing scaffolds and addressing the challenges outlined above. The process of solving these challenges will bring the next generation of the cell biology paradigm as an escape from 2D "flat biology" and a pursuit of 3D "matrix and scaffold biology." One way or another, 3D matrices will be a key contribution to the development of cell and tissue biology and clinical applications of tissue engineering.

\section{REFERENCES}

1. Lodish, H., Berk, A., Zipursky, L.S., Matsudaira, P., Baltimore, D., and Darnell, J.E. Molecular Cell Biology. New York: W.H. Freeman and Company, 2002.

2. Gartner, L.P., and Hiatt, J.L. Color Textbook of Histology. Philadelphia: Saunders, 2001.

3. Fuchs, E., Tumbar, T., and Guasch, G. Socializing with the neighbors: stem cells and their niche. Cell 116, 769, 2004.

4. Zhang, S. Beyond the Petri dish. Nat Biotech 22, 151, 2004.

5. Abbott, A. Cell culture: biology's new dimension. Nature 424, 870, 2003.

6. Cukierman, E., Pankov, R., Stevens, D.R., and Yamada, K.M. Taking cell-matrix adhesions to the third dimension. Science 294, 1708, 2001.

7. Pham, Q.P., Sharma, U., and Mikos, A.G. Electrospinning of polymeric nanofibers for tissue engineering applications: a review. Tissue Eng 12, 1197, 2006.

8. Mikos, A.G., Thorsen, A.J., Czerwonka, L.A., Bao, Y., Langer, R., Winslow, D.N., and Vacanti, J.P. Preparation and characterization of poly(lactic acid) foams. Polymer 35, 1068, 1994.

9. Hollister, S.J. Porous scaffold design for tissue engineering. Nat Mater 5, 590, 2006.

10. Shin, H., Jo, S., and Mikos, A.G. Biomimetic materials for tissue engineering. Biomaterials 24, 4353, 2003.

11. Stupp, S.I., Donners, J.J.J.M., Li, L.S., and Mata, A. Expanding frontiers in biomaterials. MRS Bulletin 30, 864, 2005.

12. Martina, M. and Hutmacher, D.W. Biodegradable polymers applied in tissue engineering research: a review. Polym Int 56, 145, 2007.

13. Hench, L.L. and Polak, J.M. Third-generation biomedical materials. Science 295, 1014, 2002.

14. Langer, R. and Tirrell, D.A. Designing materials for biology and medicine. Nature 428, 487, 2004.

15. Salvay, D.M. and Shea, L.D. Inductive tissue engineering with protein and DNA-releasing scaffolds. Mol Biosyst 2, 36, 2006.

16. Langer, R. and Vacanti, J.P. Tissue engineering. Science 260, 920, 1993.

17. Vacanti, J.P. and Langer, R. Tissue engineering: The design and fabrication of living replacement devices for surgical reconstruction and transplantation. Lancet 354, S32, 1999.

18. Griffith, L.G. and Naughton, G. Tissue engineering-current challenges and expanding opportunities. Science 295, 1009, 2002.

19. Debnath, J. and Brugge, J.S. Modelling glandular epithelial cancers in three-dimensional cultures. Nat Rev Cancer 5, 675, 2005.

20. Griffith, L.G. and Swartz, M.A. Capturing complex 3D tissue physiology in vitro. Nat Rev Mol Cell Biol 7, 211, 2006.

21. Janeway, C.A., Travers, P., Walport, M., and Shlomchik, M.J. Immuno Biology. New York: Garland Science Publishing, 2005.

22. Simmons, C.A., Alsberg, E., Hsiong, S., Kim, W.J., and Mooney, D.J. Dual growth factor delivery and controlled scaffold degradation enhance in vivo bone formation by transplanted bone marrow stromal cells. Bone 35, 562, 2004.

23. Elkayam, T., Amitay-Shaprut, S., Dvir-Ginzberg, M., Harel, T., and Cohen, S. Enhancing the drug metabolism activities 
of C3A-A human hepatocyte cell line-by tissue engineering within alginate scaffolds. Tissue Eng 12, 1357, 2006.

24. Bissell, M.J., Rizki, A., and Mian, I.S. Tissue architecture: the ultimate regulator of breast epithelial function. $\underline{\text { Curr }}$ Opin Cell Biol 15, 753, 2003.

25. Lukashev, M.E. and Werb, Z. ECM signalling: orchestrating cell behaviour and misbehaviour. Trends Cell Biol 8, 437, 1998.

26. Even-Ram, S. and Yamada, K.M. Cell migration in 3D matrix. Curr Opin Cell Biol 17, 524, 2005.

27. Muschler, G.F., Nakamoto, C., and Griffith, L.G. Engineering principles of clinical cell- based tissue engineering. J Bone Joint Surg Am 86, 1541, 2004.

28. Hollister, S.J., Levy, R.A., Chu, T.M., Halloran, J.W., and Feinberg, S.E. An image- based approach for designing and manufacturing craniofacial scaffolds. Int J Oral Max Surg 29, 67, 2000.

29. Atala, A., Bauer, S.B., Soker, S., Yoo, J.J., and Retik, A.B. Tissue-engineered autologous bladders for patients needing cystoplasty. Lancet 367, 1241, 2006.

30. Warnke, P.H., Springer, I.N.G., Wiltfang, J., Acil, Y., Eufinger, H., Wehmoller, M., Russo, P.A.J., Bolte, H., Behrens, E.S.E., and Terheyden, H. Growth and transplantation of a custom vascularised bone graft in a man. Lancet 364, 766, 2004.

31. Cesarano, J., Dellinger, J.G., Saavedra, M.P., Gill, D.D., Jamison, R.D., Grosser, B.A., Sinn-Hanlon, J.M., and Goldwasser, M.S. Customization of load-bearing hydroxyapatite lattice scaffolds. Int J Appl Ceram Tec 2, 212, 2005.

32. Palsson, B., Hubbell, J.A., Plonsey, R., and Bronzino, J.D. Tissue Engineering. Boca Raton, FL: CRC Press, 2003.

33. Gomez, N., Lu, Y., Chen, S., and Schmidt, C.E. Immobilized nerve growth factor and microtopography have distinct effects on polarization versus axon elongation in hippocampal cells in culture. Biomaterials 28, 271, 2007.

34. Zhu, X., Mills, K.L., Peters, P.R., Bahng, J.H., Liu, E.H., Shim, J., Naruse, K., Csete, M.E., Thouless, M.D., and Takayama, S. Fabrication of reconfigurable protein matrices by cracking. Nat Mater 4, 403, 2005.

35. Lin, C.Y., Kikuchi, N., and Hollister, S.J. A novel method for biomaterial scaffold internal architecture design to match bone elastic properties with desired porosity. J Biomech 37, 623, 2004.

36. Williams, J.M., Adewunmi, A., Schek, R.M., Flanagan, C.L., Krebsbach, P.H., Feinberg, S.E., Hollister, S.J., and Das, S. Bone tissue engineering using polycaprolactone scaffolds fabricated via selective laser sintering. Biomaterials 26, 4817, 2005.

37. Kotov, N.A., Liu, Y., Wang, S., Cumming, C., Eghtedari, M., Vargas, G., Motamedi, M., Nichols, J., and Cortiella, J. Inverted colloidal crystals as three-dimensional cell scaffolds. Langmuir 20, 7887, 2004.

38. Stevens, M.M. and George, J.H. Exploring and engineering the cell surface interface. Science 310, 1135, 2005.

39. Hartgerink, J.D., Beniash, E., and Stupp, S.I. Self-assembly and mineralization of peptide-amphiphile nanofibers. Science 294, 1684, 2001.

40. Vauthey, S., Santoso, S., Gong, H., Watson, N., and Zhang, S. Molecular self-assembly of surfactant-like peptides to form nanotubes and nanovesicles. Proc Natl Acad Sci U S A 99, 5355, 2002.
41. Sachlos, E., Gotora, D., and Czernuszka, J.T. Collagen scaffolds reinforced with biomimetic composite nano-sized carbonate-substituted hydroxyapatite crystals and shaped by rapid prototyping to contain internal microchannels. Tissue Eng 12, 2479, 2006.

42. Wei, G. and Ma, P.X. Structure and properties of nanohydroxyapatite/polymer composite scaffolds for bone tissue engineering. Biomaterials 25, 4749, 2004.

43. Ma, X.P. and Zhang, R. Synthetic nano-scale fibrous extracellular matrix. J Biomed Mater Res 46, 60, 1999.

44. Li, W.J., Tuli, R., Huang, X., Laquerriere, P., and Tuan, R.S. Multilineage differentiation of human mesenchymal stem cells in a three-dimensional nanofibrous scaffold. Biomaterials 26, 5158, 2005.

45. Kay, S., Thapa, A., Haberstroh, K.M., and Webster, T.J. Nanostructured polymer/nanophase ceramic composites enhance osteoblast and chondrocyte adhesion. Tissue Eng 8, 753, 2002.

46. Barry, J A., Howard, D., Shakesheff, K.M., Howdle, S.M., and Alexander, M.R. Using a core-sheath distribution of surface chemistry through 3D tissue engineering scaffolds to control cell ingress. Adv Mater 18, 1406, 2006.

47. Li, M., Mondrinos, M.J., Chen, X., Gandhi, M.R., Ko, F.K., and Lelkes, P.I. Co- electrospun poly(lactide-co-glycolide), gelatin, and elastin blends for tissue engineering scaffolds. J Biomed Mater Res A 79, 963, 2006.

48. Wei, G., and Ma, P.X. Macroporous and nanofibrous polymer scaffolds and polymer/bone-like apatite composite scaffolds generated by sugar spheres. J Biomed Mater Res A 78, 306, 2006.

49. Park, G.E., Pattison, M.A., Park, K., and Webster, T.J. Accelerated chondrocyte functions on $\mathrm{NaOH}$-treated PLGA scaffolds. Biomaterials 26, 3075, 2005.

50. Ratner, B.D., Hoffman, A.S., Schoen, F.J., and Lemons, J.E. Biomaterials Science: An Introduction to Materials in Medicine. San Diego: Elsevier Academic Press, 2004.

51. Lee, K.Y., and Mooney, D.J. Hydrogels for tissue engineering. Chem Rev 101, 1869, 2001.

52. Ma, P.X. and Elisseeff, J.H. Scaffolding in Tissue Engineering. Boca Raton, FL: CRC Press, 2006.

53. BD Bioscience. Lactate Dehydrogenase-Elevating Virus (on-line). Available at http://www.bdbiosciences.com/ldev Accessed on 02/17/08.

54. Zhang, S. Hydrogels: wet or let die. Nat Mater 3, 7, 2004.

55. Drury, J.L. and Mooney, D.J. Hydrogels for tissue engineering: scaffold design variables and applications. Biomaterials 24, 4337, 2003.

56. Hern, D.L. and Hubbell,1 J.A. Incorporation of adhesion peptides into nonadhesive hydrogels useful for tissue resurfacing. J Biomed Mater Res 39, 266, 1998.

57. Lee, J., Shanbhag, S., and Kotov, N.A. Inverted colloidal crystals as three-dimensional microenvironments for cellular co-cultures. J Mater Chem 16, 3558, 2006.

58. Rabin, O., Manuel Perez, J., Grimm, J., Wojtkiewicz, G., and Weissleder, R. An X-ray computed tomography imaging agent based on long-circulating bismuth sulphide nanoparticles. Nat Mater 5, 118, 2006.

59. Hainfeld, J.F., Slatkin, D.N., Focella, T.M., and Smilowitz, H.M. Gold nanoparticles: a new X-ray contrast agent. Br J Radiol 79, 248, 2006. 
60. Hyafil, F., Cornily, J.-C., Feig, J.E., Gordon, R., Vucic, E., Amirbekian, V., Fisher, E.A., Fuster, V., Feldman, L.J., and Fayad, Z.A. Noninvasive detection of macrophages using a nanoparticulate contrast agent for computed tomography. Nat Med 13, 636, 2007.

61. Kim, D., Park, S., Lee, J.H., Jeong, Y.Y., and Jon, S. Antibiofouling polymer-coated gold nanoparticles as a contrast agent for in vivo $\mathrm{x}$-ray computed tomography imaging. J Am Chem Soc 129, 7661, 2007.

62. Suming, L. Hydrolytic degradation characteristics of aliphatic polyesters derived from lactic and glycolic acids. J Biomed Mater Res 48, 342, 1999.

63. Yannas, I.V., Burke, J.F., Huang, C., and Gordon, P.L. Correlation of in vivo collagen degradation rate with in vitro measurements. J Biomed Mater Res 9, 623, 1975.

64. Dong, C.M., Guo, Y.Z., Qiu, K.Y., Gu, Z.W., and Feng, $X . D$. In vitro degradation and controlled release behavior of d,1-PLGA50 and PCL-b-d,1-PLGA50 copolymer microspheres. J Control Rel 107, 53, 2005.

65. Van Amerongen, M.J., Harmsen, M.C., Petersen, A.H., Kors, G., and Van Luyn, M.J.A. The enzymatic degradation of scaffolds and their replacement by vascularized extracellular matrix in the murine myocardium. Biomaterials 27, 2247, 2006.

66. Adachi, T., Osako, Y., Tanaka, M., Hojo, M., and Hollister, S.J. Framework for optimal design of porous scaffold microstructure by computational simulation of bone regeneration. Biomaterials 27, 3964, 2006.

67. Discher, D.E., Janmey, P., and Wang, Y.L. Tissue cells feel and respond to the stiffness of their substrate. Science 310, 1139, 2005.

68. Kong, H.J., Polte, T.R., Alsberg, E., and Mooney, D.J. FRET measurements of cell- traction forces and nano-scale clustering of adhesion ligands varied by substrate stiffness. Proc Natl Acad Sci U S A 102, 4300, 2005.

69. Engler, A.J., Sen, S., Sweeney, H.L., and Discher, D.E. Matrix elasticity directs stem cell lineage specification. Cell 126, 677, 2006.

70. Feng, Q., Chai, C., Jiang, X.S., Leong, K.W., and Mao, H.Q. Expansion of engrafting human hematopoietic stem/ progenitor cells in three-dimensional scaffolds with surfaceimmobilized fibronectin. J Biomed Mater Res A 78, 781, 2006.

71. Chastain, S.R., Kundu, A.K., Dhar, S., Calvert, J.W., and Putnam, A.J. Adhesion of mesenchymal stem cells to polymer scaffolds occurs via distinct ECM ligands and controls their osteogenic differentiation. J Biomed Mater Res A 78, 73, 2006.

72. Patel, P.N., Gobin, A.S., West, J.L., and Patrick, C.W. Poly (ethylene glycol) hydrogel system supports preadipocyte viability, adhesion, and proliferation. Tissue Eng 11, 1498, 2005.

73. Prestwich, G.D., Marecak, D.M., Marecek, J.F., Vercruysse, K.P., and Ziebell, M.R. Controlled chemical modification of hyaluronic acid: synthesis, applications, and biodegradation of hydrazide derivatives. J Control Rel 53, 93, 1998.

74. Brinkman, W.T., Nagapudi, K., Thomas, B.S., and Chaikof, E.L. Photo-cross-linking of type i collagen gels in the presence of smooth muscle cells: mechanical properties, cell viability, and function. Biomacromolecules 4, 890, 2003.
75. Saltzman, W.M. and Olbricht, W.L. Building drug delivery into tissue engineering. Nat Rev Drug Discov 1, 177, 2002.

76. Richardson, T.P., Peters, M.C., Ennett, A.B., and Mooney, D.J. Polymeric system for dual growth factor delivery. Nat Biotech 19, 1029, 2001.

77. Edwards, P.C., Ruggiero, S., Fantasia, J., Burakoff, R., Moorji, S.M., Paric, E., Razzano, P., Grande, D.A., and Mason, J.M. Sonic hedgehog gene-enhanced tissue engineering for bone regeneration. Gene Ther 12, 75, 2004.

78. Shi, X., Sitharaman, B., Pham, Q.P., Liang, F., Wu, K., Edward Billups, W., Wilson, L.J., and Mikos, A.G. Fabrication of porous ultra-short single-walled carbon nanotube nanocomposite scaffolds for bone tissue engineering. Biomaterials 28, 4078, 2007.

79. Singh, R., Pantarotto, D., Lacerda, L., Pastorin, G., Klumpp, C., Prato, M., Bianco, A., and Kostarelos, K. Tissue biodistribution and blood clearance rates of intravenously administered carbon nanotube radiotracers. Proc Natl Acad Sci U S A 103, 3357, 2006.

80. Lovat, V., Pantarotto, D., Lagostena, L., Cacciari, B., Grandolfo, M., Righi, M., Spalluto, G., Prato, M., and Ballerini, L. Carbon nanotube substrates boost neuronal electrical signaling. Nano Lett. 5, 1107, 2005.

81. Gheith, M.K., Pappas, T.C., Liopo, A.V., Sinani, V.A., Shim, B.S., Motamedi, M., Wicksted, J.P., and Kotov, N.A. Stimulation of neural cells by lateral currents in conductive layer-by-layer films of single-walled carbon nanotubes. Advanced Materials 18, 2975, 2006.

82. Jan, E., and Kotov, N.A. Successful Differentiation of Mouse Neural Stem Cells on Layer-by-Layer Assembled Single-Walled Carbon Nanotube Composite. Nano Lett. 7, 1123, 2007.

83. Wilson, C.J., Clegg, R.E., Leavesley, D.I., and Pearcy, M.J. Mediation of biomaterial-cell interactions by adsorbed proteins: A review. Tissue Eng 11, 1, 2005.

84. Allen, L.T., Tosetto, M., Miller, I.S., O'Connor, D.P., Penney, S.C., Lynch, I., Keenan, A.K., Pennington, S.R., Dawson, K.A., and Gallagher, W.M. Surface-induced changes in protein adsorption and implications for cellular phenotypic responses to surface interaction. Biomaterials 27, 3096, 2006.

85. Chen, Y.M., Shiraishi, N., Satokawa, H., Kakugo, A., Narita, T., Gong, J.P., Osada, Y., Yamamoto, K., and Ando, J. Cultivation of endothelial cells on adhesive protein-free synthetic polymer gels. Biomaterials 26, 4588, 2005.

86. Schneider, G.B., English, A., Abraham, M., Zaharias, R., Stanford, C., and Keller, J. The effect of hydrogel charge density on cell attachment. Biomaterials 25, 3023, 2004.

87. Keselowsky, B.G., Collard, D.M., and Garcia, A.J. Integrin binding specificity regulates biomaterial surface chemistry effects on cell differentiation. Proc Natl Acad Sci U S A 102, 5953, 2005.

88. Zhiyong, T., Ying, W., Paul, P., and Nicholas A., K. Biomedical applications of layer-by- layer assembly: From biomimetics to tissue engineering. Adv Mater 18, 3203, 2006.

89. Decher, G. Fuzzy nanoassemblies: Toward layered polymeric multicomposites. Science 277, 1232, 1997.

90. Mehta, G., Kiel, M.J., Lee, J.W., Kotov, N.A., Linderman, J.J., and Takayama, S. Polyelectrolyte-clay-protein layer films on microfluidic PDMS bioreactor surfaces for primary murine bone marrow culture. Adv Funct Mater 17, 2701, 2007. 
91. Wood, K.C., Chuang, H.F., Batten, R.D., Lynn, D.M., and Hammond, P.T. Controlling interlayer diffusion to achieve sustained, multiagent delivery from layer-by-layer thin films. Proc Natl Acad Sci U S A 103, 10207, 2006.

92. Dierich, A., Guen, E., Messaddeq, N., Stoltz, J., Netter, P., Schaaf, P., Voegel, J., and Benkirane-Jessel, N. Bone formation mediated by synergy-acting growth factors embedded in a polyelectrolyte multilayer film. Adv Mater 19, 693, 2007.

93. Chen, H.Y., Elkasabi, Y., and Lahann, J. Surface modification of confined microgeometries via vapor-deposited polymer coatings. J. Am. Chem. Soc. 128, 374, 2006.

94. Datta, N., Pham, Q.P., Sharma, U., Sikavitsas, V.I., Jansen, J.A., and Mikos, A.G. In vitro generated extracellular matrix and fluid shear stress synergistically enhance 3D osteoblastic differentiation. Proc Natl Acad Sci U S A 103, 2488, 2006.

95. Weaver, V.M., Petersen, O.W., Wang, F., Larabell, C.A., Briand, P., Damsky, C., and Bissell, M.J. Reversion of the malignant phenotype of human breast cells in threedimensional culture and in vivo by integrin blocking antibodies. J. Cell Biol. 137, 231, 1997.

96. Lutolf, M.P., Weber, F.E., Schmoekel, H.G., Schense, J.C., Kohler, T., Muller, R., and Hubbell, J.A. Repair of bone defects using synthetic mimetics of collagenous extracellular matrices. Nat Biotech 21, 513, 2003.

97. Moutos, F.T., Freed, L.E., and Guilak, F. A biomimetic three-dimensional woven composite scaffold for functional tissue engineering of cartilage. Nat Mater 6, 162, 2007.

98. Hohlfeld, J., de Buys Roessingh, A., Hirt-Burri, N., Chaubert, P., Gerber, S., Scaletta, C., Hohlfeld, P., and Applegate, L.A. Tissue engineered fetal skin constructs for paediatric burns. Lancet 366, 840, 2005.

99. Seo, S.J., Kim, I.Y., Choi, Y.J., Akaike, T., and Cho, C.S. Enhanced liver functions of hepatocytes cocultured with NIH 3T3 in the alginate/galactosylated chitosan scaffold. Biomaterials 27, 1487, 2006.

100. Niklason, L.E., Gao, J., Abbott, W.M., Hirschi, K.K., Houser, S., Marini, R., and Langer, R. Functional arteries grown in vitro. Science 284, 489, 1999.

101. Levenberg, S., Rouwkema, J., Macdonald, M., Garfein, E.S., Kohane, D.S., Darland, D.C., Marini, R., van Blitterswijk, C.A., Mulligan, R.C., D'Amore, P.A., and Langer, R. Engineering vascularized skeletal muscle tissue. Nat Biotech 23, 879, 2005.

102. Wang, G.-J., Hsu, Y.-F., Hsu, S.-H., and Horng, R. JSR photolithography based microvessel scaffold fabrication and cell seeding. Biomed Microdevices 8, 17, 2006.

103. Khademhosseini, A., Ferreira, L., Blumling Iii, J., Yeh, J., Karp, J.M., Fukuda, J., and Langer, R. Co-culture of human embryonic stem cells with murine embryonic fibroblasts on microwell-patterned substrates. Biomaterials 27, 5968, 2006.

104. Li, L. and Fourkas, J.T. Multiphoton polymerization. Materials Today 10, 30, 2007.

105. Uludag, H., De-Vos, P., and Tresco, P.A. Technology of mammalian cell encapsulation. Adv Drug Deliver Rev 42, 29, 2000.

106. Bunger, C.M., Tiefenbach, B., Jahnke, A., Gerlach, C., Freier, T., Schmitz, K.P., Hopt, U.T., Schareck, W., Klar, E., and de Vos, P. Deletion of the tissue response against alginate-pll capsules by temporary release of co-encapsulated steroids. Biomaterials 26, 2353, 2005.
107. Zhang, S. Fabrication of novel biomaterials through molecular self-assembly. Nat Biotech 21, 1171, 2003.

108. Kleinman, H.K. and Martin, G.R. Matrigel: basement membrane matrix with biological activity. Semin Cancer Biol 15, 378, 2005.

109. Blomback, B. and Bark, N. Fibrinopeptides and fibrin gel structure. Biophys Chem 112, 147, 2004.

110. Augst, A.D., Kong, H.J., and Mooney, D.J. Alginate hydrogels as biomaterials. Macromol Biosci 6, 623, 2006.

111. Kisiday, J., Jin, M., Kurz, B., Hung, H., Semino, C., Zhang, S., and Grodzinsky, A.J. Self-assembling peptide hydrogel fosters chondrocyte extracellular matrix production and cell division: implications for cartilage tissue repair. Proc Natl Acad Sci U S A 99, 9996, 2002.

112. Elisseeff, J., Anseth, K., Sims, D., McIntosh, W., Randolph, M., and Langer, R. Transdermal photopolymerization for minimally invasive implantation. Proc Natl Acad Sci U S A 96, 3104, 1999.

113. Ellis-Behnke, R.G., Liang, Y.X., You, S.W., Tay, D.K.C., Zhang, S., So, K.F., and Schneider, G.E. Nano neuro knitting: Peptide nanofiber scaffold for brain repair and axon regeneration with functional return of vision. Proc Natl Acad Sci U S A 103, 5054, 2006.

114. Silva, G.A., Czeisler, C., Niece, K.L., Beniash, E., Harrington, D.A., Kessler, J.A., and Stupp, S.I. Selective differentiation of neural progenitor cells by high-epitope density nanofibers. Science 303, 1352, 2004.

115. Li, Y., Tseng, Y.D., Kwon, S.Y., d'Espaux, L., Bunch, J.S., McEuen, P.L., and Luo, D. Controlled assembly of dendrimer-like DNA. Nat Mater 3, 38, 2004.

116. Um, S.H., Lee, J.B., Park, N., Kwon, S.Y., Umbach, C.C., and Luo, D. Enzyme-catalysed assembly of DNA hydrogel. Nat Mater 5, 797, 2006.

117. Dikovsky, D., Bianco-Peled, H., and Seliktar, D. The effect of structural alterations of PEG-fibrinogen hydrogel scaffolds on 3-D cellular morphology and cellular migration. Biomaterials 27, 1496, 2006.

118. Lutolf, M.P., Lauer-Fields, J.L., Schmoekel, H.G., Metters, A.T., Weber, F.E., Fields, G.B., and Hubbell, J.A. Synthetic matrix metalloproteinase-sensitive hydrogels for the conduction of tissue regeneration: Engineering cell-invasion characteristics. Proc Natl Acad Sci U S A 100, 5413, 2003.

119. Lutolf, M.P., Raeber, G.P., Zisch, A.H., Tirelli, N., and Hubbell, J.A. Cell-responsive synthetic hydrogels. Adv Mater 15, 888, 2003.

120. Guler, M.O., Soukasene, S., Hulvat, J.F., and Stupp, S.I. Presentation and recognition of biotin on nanofibers formed by branched peptide amphiphiles. Nano Lett. 5, 249, 2005.

121. Albrecht, D.R., Underhill, G.H., Wassermann, T.B., Sah, R.L., and Bhatia, S.N. Probing the role of multicellular organization in three-dimensional microenvironments. Nat Meth 3, 369, 2006.

122. Kuo, C.K. and Ma, P.X. Ionically crosslinked alginate hydrogels as scaffolds for tissue engineering: Part 1. Structure, gelation rate and mechanical properties. Biomaterials 22, 511, 2001.

123. Wang, D.A., Williams, C.G., Li, Q., Sharma, B., and Elisseeff, J.H. Synthesis and characterization of a novel degradable phosphate-containing hydrogel. Biomaterials 24, 3969, 2003. 
124. Sharma, B., Williams, C.G., Kim, T.K., Sun, D., Malik, A., Khan, M., Leong, K., and Elisseeff, J.H. Designing zonal organization into tissue-engineered cartilage. Tissue Eng 13, 405, 2007.

125. Stupp, S.I. Biomaterials for regenerative medicine. MRS Bull 30, 546, 2005.

126. LaBean, T. Hydrogels: DNA bulks up. Nat Mater 5, 767, 2006.

127. Almany, L. and Seliktar, D. Biosynthetic hydrogel scaffolds made from fibrinogen and polyethylene glycol for $3 \mathrm{D}$ cell cultures. Biomaterials 26, 2467, 2005.

128. Li, M.L., Aggeler, J., Farson, D.A., Hatier, C., Hassell, J., and Bissell, M.J. Influence of a reconstituted basement membrane and its components on casein gene expression and secretion in mouse mammary epithelial cells. Proc Natl Acad Sci U S A 84, 136, 1987.

129. Zahir, N. and Weaver, V.M. Death in the third dimension: apoptosis regulation and tissue architecture. Curr Opin Genet Dev 14, 71, 2004.

130. Larsen, M., Tremblay, M.L., and Yamada, K.M. Phosphatases in cell-matrix adhesion and migration. Nat Rev Mol Cell Biol 4, 700, 2003.

131. Zaman, M.H., Trapani, L.M., Sieminski, A.L., MacKellar, D., Gong, H., Kamm, R.D., Wells, A., Lauffenburger, D.A., and Matsudaira, P. Migration of tumor cells in 3D matrices is governed by matrix stiffness along with cell-matrix adhesion and proteolysis. Proc Natl Acad Sci U S A 103, 10889, 2006.

132. Hotary, K.B., Allen, E.D., Brooks, P.C., Datta, N.S., Long, M.W., and Weiss, S.J. Membrane type I matrix metalloproteinase usurps tumor growth control imposed by the three-dimensional extracellular matrix. Cell 114, 33, 2003.

133. Orive, G., Hernandez, R.M., Gascon, A.R., Calafiore, R., Chang, T.M.S., Vos, P.D., Hortelano, G., Hunkeler, D., Lacik, I., Shapiro, A.M.J., and Pedraz, J.L. Cell encapsulation: promise and progress. Nat Med 9, 104, 2003.

134. Pangas, S.A., Saudye, H., Shea, L.D., and Woodruff, T.K. Novel approach for the three-dimensional culture of granulosa cell-oocyte complexes. Tissue Eng 9, 1013, 2003.

135. Xu, M., Kreeger, P.K., Shea, L.D., and Woodruff, T.K. Tissue-engineered follicles produce live, fertile offspring. Tissue Eng 12, 2739, 2006.

136. Kreeger, P.K., Deck, J.W., Woodruff, T.K., and Shea, L.D. The in vitro regulation of ovarian follicle development using alginate-extracellular matrix gels. Biomaterials 27, 714, 2006.

137. West, E.R., Xu, M., Woodruff, T.K., and Shea, L.D. Physical properties of alginate hydrogels and their effects on in vitro follicle development. Biomaterials 28, 4439, 2007.

138. Holmes, T.C., de Lacalle, S., Su, X., Liu, G., Rich, A., and Zhang, S. Extensive neurite outgrowth and active synapse formation on self-assembling peptide scaffolds. Proc Natl Acad Sci U S A 97, 6728, 2000.

139. Schense, J.C., Bloch, J., Aebischer, P., and Hubbell, J.A. Enzymatic incorporation of bioactive peptides into fibrin matrices enhances neurite extension. Nat Biotech 18, 415, 2000.

140. Wang, F., Weaver, V.M., Petersen, O.W., Larabell, C.A., Dedhar, S., Briand, P., Lupu, R., and Bissell, M.J. Reciprocal interactions between beta 1-integrin and epidermal growth factor receptor in three-dimensional basement membrane breast cultures: a different perspective in epithelial biology. Proc Natl Acad Sci U S A 95, 14821, 1998.

141. Weaver, V.M., Lelievre, S., Lakins, J.N., Chrenek, M.A., Jones, J.C.R., Giancotti, F., Werb, Z., and Bissell, M.J. B-4 integrin-dependent formation of polarized three-dimensional architecture confers resistance to apoptosis in normal and malignant mammary epithelium. Cancer Cell 2, 205, 2002.

142. Lanza, R.P., Langer, R., and Vacanti, J. Principles of Tissue Engineering. San Diego: Academic Press, 2000.

143. Whang, K., Thomas, C.H., Healy, K.E., and Nuber, G. A novel method to fabricate bioabsorbable scaffolds. Polymer 36, 837, 1995.

144. Mooney, D.J., Baldwin, D.F., Suh, N.P., Vacanti, J.P., and Langer, R. Novel approach to fabricate porous sponges of poly(lactic-co-glycolic acid) without the use of organic solvents. Biomaterials 17, 1417, 1996.

145. Murphy, W.L., Dennis, R.G., Kileny, J.L., and Mooney, D.J. Salt fusion: an approach to improve pore interconnectivity within tissue engineering scaffolds. Tissue Eng 8, 43, 2002.

146. Ma, P.X. and Choi, J.W. Biodegradable polymer scaffolds with well-defined interconnected spherical pore network. Tissue Eng 7, 23, 2001.

147. Hou, Q., Grijpma, D.W., and Feijen, J. Preparation of interconnected highly porous polymeric structures by a replication and freeze-drying process. J Biomed Mater Res B 67, 732, 2003.

148. Harris, L.D., Kim, B.S., and Mooney, D.J. Open pore biodegradable matrices formed with gas foaming. J Biomed Mater Res 42, 396, 1998.

149. Chew, S.Y., Wen, J., Yim, E.K.F., and Leong, K.W. Sustained release of proteins from electrospun biodegradable fibers. Biomacromolecules 6, 2017, 2005.

150. Li, D., Ouyang, G., McCann, J.T., and Xia, Y. Collecting electrospun nanofibers with patterned electrodes. Nano Lett. 5, 913, 2005.

151. Zhang, P.C., Zhang, Y., Ouyang, H., Lim, C.T., Ramakrishna, S., and Huang, Z.M. Electrospinning of gelatin fibers and gelatin/PCL composite fibrous scaffolds. J Biomed Mater Res B 72, 156, 2005.

152. Pham, Q.P., Sharma, U., and Mikos, A.G. Electrospun poly (e-caprolactone) microfiber and multilayer nanofiber/microfiber scaffolds: Characterization of scaffolds and measurement of cellular Infiltration. Biomacromolecules 7, 2796, 2006.

153. Lu, L. and Mikos, A.G. The importance of new processing techniques in tissue engineering. MRS Bull 21, 28, 1996.

154. Shea, L.D., Smiley, E., Bonadio, J., and Mooney, D.J. DNA delivery from polymer matrices for tissue engineering. Nat Biotech 17, 551, 1999.

155. Teng, Y.D., Lavik, E.B., Qu, X., Park, K.I., Ourednik, J., Zurakowski, D., Langer, R., and Snyder, E.Y. Functional recovery following traumatic spinal cord injury mediated by a unique polymer scaffold seeded with neural stem cells. Proc Natl Acad Sci U S A 99, 3024, 2002.

156. Chen, V.J. and Ma, P.X. Nano-fibrous poly(lactic acid) scaffolds with interconnected spherical macropores. Biomaterials 25, 2065, 2004.

157. Chen, V.J., Smith, L.A., and Ma, P.X. Bone regeneration on computer-designed nano-fibrous scaffolds. Biomaterials 27, 3973, 2006. 
158. Cuddihy, J.M. and Kotov, A.N. Poly(lactic-co-glycolic acid) bone scaffolds with inverted colloidal crystal geometry. Accepted.

159. Stachowiak, A.N., Bershteyn, A., Tzatzalos, E., and Irvine, D.J. Bioactive hydrogels with an ordered cellular structure combine interconnected macroporosity and robust mechanical properties. Adv Mater 17, 399, 2005.

160. Kim, S.S., Park, M.S., Jeon, O., Choi, C.Y., and Kim, B.S. Poly(lactide-co- glycolide)/hydroxyapatite composite scaffolds for bone tissue engineering. Biomaterials 27, 1399, 2006.

161. Luu, Y.K., Kim, K., Hsiao, B.S., Chu, B., and Hadjiargyrou, M. Development of a nanostructured DNA delivery scaffold via electrospinning of PLGA and PLA-PEG block copolymers. J Control Rel 89, 341, 2003.

162. McCann, J.T., Chen, J.I.L., Li, D., Ye, Z.-G., and Xia, Y. Electrospinning of polycrystalline barium titanate nanofibers with controllable morphology and alignment. Chem Phys Lett 424, 162, 2006.

163. Lee, S.B., Kim, Y.H., Chong, M.S., Hong, S.H., and Lee, Y.M. Study of gelatin- containing artificial skin V: fabrication of gelatin scaffolds using a salt-leaching method. Biomaterials 26, 1961, 2005.

164. Bhattarai, N., Li, Z., Edmondson, D., and Zhang, M. Alginatebased nanofibrous scaffolds: structural, mechanical, and biological properties. Adv Mater 18, 1463, 2006.

165. Pattison, M.A., Wurster, S., Webster, T.J., and Haberstroh, K.M. Three-dimensional, nano-structured PLGA scaffolds for bladder tissue replacement applications. Biomaterials 26, 2491, 2005.

166. Woo, K.M., Chen, V.J., and Ma, P.X. Nano-fibrous scaffolding architecture selectively enhances protein adsorption contributing to cell attachment. J Biomed Mater Res A 67, 531, 2003.

167. Li, W.J., Jiang, Y.J., and Tuan, R.S. Chondrocyte phenotype in engineered fibrous matrix is regulated by fiber size. Tissue Eng 12, 1775, 2006.

168. Zhong, S., Teo, W.E., Zhu, X., Beuerman, R.W., Ramakrishna, S., and Yung, L.Y.L. An aligned nanofibrous collagen scaffold by electrospinning and its effects on in vitro fibroblast culture. J Biomed Mater Res A 79, 456, 2006.

169. Karageorgiou, V. and Kaplan, D. Porosity of 3D biomaterial scaffolds and osteogenesis. Biomaterials 26, 5474, 2005.

170. Uebersax, L., Hagenmuller, H., Hofmann, S., Gruenblatt, E., Muller, R., Vunjaknovakovic, G., Kaplan, D.L., Merkle, H.P., and Meinel, L. Effect of scaffold design on bone morphology in-vitro. Tissue Eng 12, 3417, 2006.

171. Nelson, C.M., VanDuijn, M.M., Inman, J.L., Fletcher, D.A., and Bissell, M.J. Tissue geometry determines sites of mammary branching morphogenesis in organotypic cultures. Science 314, 298, 2006.

172. Lu, H.F., Chua, K.N., Zhang, P.C., Lim, W.S., Ramakrishna, S., Leong, K.W., and Mao, H.Q. Three-dimensional coculture of rat hepatocyte spheroids and NIH/3T3 fibroblasts enhances hepatocyte functional maintenance. Acta Biomater 1, 399, 2005.

173. Fischbach, C., Chen, R., Matsumoto, T., Schmelzle, T., Brugge, J.S., Polverini, P.J., and Mooney, D.J. Engineering tumors with 3D scaffolds. Nat Meth 40, 855, 2007.

174. Wilson, A. and Trumpp, A. Bone-marrow haematopoieticstem-cell niches. Nat Rev Immunol 6, 93, 2006.
175. Poznansky, M.C., Evans, R.H., Foxall, R.B., Olszak, I.T., Piascik, A.H., Hartman, K.E., Brander, C., Meyer, T.H., Pykett, M.J., Chabner, K.T., Kalams, S.A., Rosenzweig, M., and Scadden, D.T. Efficient generation of human T cells from a tissue-engineered thymic organoid. Nat Biotech 18, 729, 2000.

176. Hutmacher, D.W., Sittinger, M., and Risbud, M.V. Scaffoldbased tissue engineering: rationale for computer-aided design and solid free-form fabrication systems. Trends Biotechnol 22, 354, 2004.

177. Levy, R.A., Chu, T.M., Halloran, J.W., Feinberg, S.E., and Hollister, S. CT-generated porous hydroxyapatite orbital floor prosthesis as a prototype bioimplant. AJNR Am J Neuroradiol 18, 1522, 1997.

178. Lee, G. and Barlow, J.W. Selective laser sintering of bioceramic materials for implants. SFF Symposium, Austin, TX, 376, 1993.

179. Dellinger, G.J., Cesarano, C. J., Jamison, D.R. Robotic deposition of model hydroxyapatite scaffolds with multiple architectures and multiscale porosity for bone tissue engineering. J Biomed Mater Res A 82, 383, 2007.

180. Sherwood, J.K., Riley, S.L., Palazzolo, R., Brown, S.C., Monkhouse, D.C., Coates, M., Griffith, L.G., Landeen, L.K., and Ratcliffe, A. A three-dimensional osteochondral composite scaffold for articular cartilage repair. Biomaterials 23, 4739, 2002.

181. Seet, K.K., Mizeikis, V., Juodkazis, S., and Misawa, H. Threedimensional horizontal circular spiral photonic crystals with stop gaps below 1 mu m. Appl Phy Lett 88, 221101, 2006.

182. Hahn, M.S., Miller J. S., West J. L. Three-dimensional biochemical and biomechanical patterning of hydrogels for guiding cell behavior. Adv Mater 18, 2679, 2006.

183. Sun, W., Darling, A., Starly, B., and Nam, J. Computeraided tissue engineering: overview, scope and challenges. Biotechnol Appl Biochem 39, 29, 2004.

184. Wettergreen, M., Bucklen, B., Sun, W., and Liebschner, M. Computer-aided tissue engineering of a human vertebral body. Ann Biomed Eng 33, 1333, 2005.

185. Hollister, S.J. and Kikuchi, N. Homogenization theory and digital imaging: a basis for studying the mechanics and design principles of bone tissue. Biotechnol Bioeng 43, 586, 1994.

186. Leong, K.F., Cheah, C.M., and Chua, C.K. Solid freeform fabrication of three-dimensional scaffolds for engineering replacement tissues and organs. Biomaterials 24, 2363, 2003.

187. Yeong, W.Y., Chua, C.K., Leong, K.F., and Chandrasekaran, $\mathrm{M}$. Rapid prototyping in tissue engineering: challenges and potential. Trends Biotechnol 22, 643, 2004.

188. Russias, J., Saiz, E., Nalla, R., and Tomsia, A. Microspheres as building blocks for hydroxyapatite/polylactide biodegradable composites. J Mater Sci 41, 5127, 2006.

189. Mondrinos, M.J., Dembzynski, R., Lu, L., Byrapogu, V.K.C., Wootton, D.M., Lelkes, P.I., and Zhou, J. Porogenbased solid freeform fabrication of polycaprolactonecalcium phosphate scaffolds for tissue engineering. Biomaterials 27, 4399, 2006.

190. Wahl, D., Sachlos, E., Liu, C., and Czernuszka, J. Controlling the processing of collagen- hydroxyapatite scaffolds for bone tissue engineering. J Mater Sci 18, 201, 2007.

191. Cao, T., Ho, K.H., and Teoh, S.H. Scaffold design and in vitro study of osteochondral coculture in a three-dimensional 
porous polycaprolactone scaffold fabricated by fused deposition modeling. Tissue Eng 9, 103, 2003.

192. Cooke, M.N., Fisher, J.P., Dean, D., Rimnac, C., and Mikos, A.G. Use of stereolithography to manufacture critical-sized 3D biodegradable scaffolds for bone ingrowth. J Biomed Mater Res B 64, 65, 2003.

193. Rimell, J.T. and Marquis, P.M. Selective laser sintering of ultra high molecular weight polyethylene for clinical applications. J Biomed Mater Res 53, 414, 2000.

194. Taboas, J.M., Maddox, R.D., Krebsbach, P.H., and Hollister, S.J. Indirect solid free form fabrication of local and global porous, biomimetic and composite 3D polymer-ceramic scaffolds. Biomaterials 24, 181, 2003.

195. Cohen, D.L., Malone, E., Lipson, H., and Bonassar, L.J. Direct freeform fabrication of seeded hydrogels in arbitrary geometries. Tissue Eng 12, 1325, 2006.

196. Wang, X., Yan, Y., Pan, Y., Xiong, Z., Liu, H., Cheng, J., Liu, F., Lin, F., Wu, R., Zhang, R., and Lu, Q. Generation of three-dimensional hepatocyte/gelatin structures with rapid prototyping system. Tissue Eng 12, 83, 2006.

197. Xu, T., Jin, J., Gregory, C., Hickman, J.J., and Boland, T. Inkjet printing of viable mammalian cells. Biomaterials $\mathbf{2 6}$, 93, 2005.

198. Tsang, V.L., Chen, A.A., Cho, L.M., Jadin, K.D., Sah, R.L., DeLong, S., West, J.L., and Bhatia, S.N. Fabrication of 3D hepatic tissues by additive photopatterning of cellular hydrogels. FASEB J 21, 790, 2007.

199. Partee, B., Hollister, S.J., and Das, S. Selective laser sintering of polycaprolactone bone tissue engineering. Materials Research Society, AA9.9.1, 2005.

200. Moroni, L., De-Wijn, J.R., and Van-Blitterswijk, C.A. 3D fiber-deposited scaffolds for tissue engineering: Influence of pores geometry and architecture on dynamic mechanical properties. Biomaterials 27, 974, 2006.

201. Hung, C.T., Lima, E.G., Mauck, R.L., Taki, E., LeRoux, M.A., Lu, H.H., Stark, R.G., Guo, X.E., and Ateshian, G.A. Anatomically shaped osteochondral constructs for articular cartilage repair. J Biomech 36, 1853, 2003.

202. Kaplan, D.L., Moon, R.T., and Vunjak-Novakovic, G. It takes a village to grow a tissue. Nat Biotech 23, 1237, 2005.

203. Liao, E., Yaszemski, M., Krebsbach, P., and Hollister, S. Tissue-engineered cartilage constructs using composite hyaluronic acid/collagen I hydrogels and designed poly(propylene fumarate) scaffolds. Tissue Eng 13, 537, 2007.

204. Xu, J., Ma, M., and Purcell, W.M. Characterisation of some cytotoxic endpoints using rat liver and HepG2 spheroids as in vitro models and their application in hepatotoxicity studies. II. Spheroid cell spreading inhibition as a new cytotoxic marker. Toxicol Appl Pharm 189, 112, 2003.

205. MacNeil, S. Progress and opportunities for tissue-engineered skin. Nature 445, 874, 2007.

206. The Interagency Coordinating Committee on the Validation of Alternative Methods, 2004 (on-line). Available at http:// iccvam.niehs.nih.gov. Accessed on 02/17/08.

Address reprint requests to: Nicholas A. Kotov, Ph.D. University of Michigan 3074 H.H. Dow Building 2300 Hayward Street Ann Arbor, MI 48109

E-mail: kotov@umich.edu 


\section{This article has been cited by:}

1. Travis J. Klein , Jos Malda , Robert L. Sah , Dietmar W. Hutmacher . 2009. Tissue Engineering of Articular Cartilage with Biomimetic ZonesTissue Engineering of Articular Cartilage with Biomimetic Zones. Tissue Engineering Part B: Reviews 15:2, 143-157. [Abstract] [Full Text] [PDF] [PDF Plus]

2. Stephanie Grenier, Martin Sandig, Kibret Mequanint. Smooth Muscle $\alpha$-Actin and Calponin Expression and Extracellular Matrix Production of Human Coronary Artery Smooth Muscle Cells in 3D ScaffoldsSmooth Muscle $\boldsymbol{\alpha}$-Actin and Calponin Expression and Extracellular Matrix Production of Human Coronary Artery Smooth Muscle Cells in 3D Scaffolds. Tissue Engineering Part A, ahead of print. [Abstract] [PDF] [PDF Plus]

3. Meghan J. Cuddihy, Nicholas A. Kotov . 2008. Poly(lactic-co-glycolic acid) Bone Scaffolds with Inverted Colloidal Crystal GeometryPoly(lactic-co-glycolic acid) Bone Scaffolds with Inverted Colloidal Crystal Geometry. Tissue Engineering Part A 14:10, 1639-1649. [Abstract] [PDF] [PDF Plus] 